\title{
Li-containing alloys beneficial for stabilizing lithium anode: a review
}

\author{
Xingxing $\mathrm{Gu}^{1}$, Jing Dong${ }^{2}$, and Chao $\mathrm{Lai}^{2}$ \\ ${ }^{1}$ Chongqing Technology and Business University \\ ${ }^{2}$ Jiangsu Normal University
}

August 17, 2020

\begin{abstract}
Due to the soaring growth of the electric vehicles and grid energy storage markets, the high-safety and high-energy-density battery storage systems are urgent needed. Lithium metal anode with highest theoretical specific capacity (3860 mA.h.g-1) and the lowest electrochemical potential $(-3.04 \mathrm{~V}$ vs standard hydrogen electrode) is regarded as the ultimate choice for the high energy density batteries. However, its safety problems as well as the low Coulombic efficiency during the Li plating and stripping processes significantly limit the commercialization of lithium metal batteries. Recently, Li-containing alloys have demonstrated vital roles in inhibiting lithium dendrite growth, controlling interfacial reactions and enhancing the Coulombic efficiency as well as cycle life. Accordingly, in this perspective, the progresses of lithium alloys for robust, stable and dendrite free anode for rechargeable lithium metal batteries are summarized. The challenges and future focus research of lithium-containing alloys in lithium metal batteries are also discussed.
\end{abstract}

REVIEW ARTICLE

Li-containing alloys beneficial for stabilizing lithium anode: a review

Xingxing $\mathrm{Gu}^{1+} \mid$ Jing Dong ${ }^{2+} \mid$ Chao Lai*2

${ }^{1}$ Chongqing Key Laboratory of Catalysis and New Environmental Materials, College of Environment and Resources, Chong

\section{Introduction}

The metallic lithium as an anode in a rechargeable battery was first explored by Whittingham in 1970s at Exxon and realized commercialization by Moli Energy in the late 1980s[1-3], but frequent accidents, including fires caused by dendrite formation, brought serious safety issues to public attention, which leaded to the Moli Energy company ultimately recall all the cells. The first commercialization of lithium-metal anode rechargeable batteries ended in failure. Then Sony company developed the graphite anodes to replace metallic $\mathrm{Li}$ anode, matched with the $\mathrm{LiCoO}_{2}$ cathode, successfully built reliable Li-ion cells that have been widely used until now $[2,4-6]$. However, with the booming growth in consumer electronic devices and electric vehicles, even the state-of-the-art lithium ion batteries (LIBs) using graphite anodes (with a theoretical specific capacity of $372 \mathrm{~mA}^{*} \mathrm{~h}^{*} \mathrm{~g}^{-1}$ ) have almost reached their theoretical energy density $\left(350 \mathrm{Wh}^{*} \mathrm{~kg}^{-1}\right)$, cannot provide the high energy density required for their demands[7-10].

Therefore, recently, particularly in recent 10 years, the rechargeable lithium metal batteries using the $\mathrm{Li}$ anode has acquired unprecedented attentions as it has the unsurpassably highest theoretical capacity (3860 
$\mathrm{mA}^{*} \mathrm{~h}^{*} \mathrm{~g}^{-1}$, or $2061 \mathrm{~mA}^{*} \mathrm{~h}^{*} \mathrm{~cm}^{-3}$ ) and lowest electrochemical potential (-3.04 V versus the standard hydrogen electrode) [2, 11-15]. Additionally, with rapid development of cathodes alternative to conventional intercalation cathodes used in state-of-the-art Li-ion batteries, i.e., the sulfur (S) cathode (with energy density of [?]2600 $\mathrm{Wh}^{*} \mathrm{~kg}^{-1}$ ) for the Li-S battery and the oxygen cathode (with energy density of [?]11140 $\mathrm{Wh}^{*} \mathrm{~kg}^{-1}$ ) for the Li-air battery[16, 17], have undoubtedly hastened the arrival of rechargeable Li metal batteries.

However, the safety issues by using the $\mathrm{Li}$ anode as well as its poor cycle stability and low Coulombic efficiency are still not overcome and hinds its practical applications. Tremendous efforts have been devoted to solving the notorious lithium dendrite problem by employing advanced electrolytes, separators, and novel electrode materials/structures. In the aspect of electrolyte, increasing the concentrations of lithium salts and adding inorganic or organic additives in electrolyte could not only benefit to stabilize the spontaneous solid electrolyte interphase (SEI) films to reduce the side reactions happening, but also control the nucleation and growth of metallic lithium, thus enhancing the stabilities of lithium anodes during the stripping and plating processes[18-22]. Recently, our group employed octaphenyl polyoxyethylene as an electrolyte additive to enable a stable complex layer on the surface of the lithium anode. This surface layer not only promoted uniform lithium deposition, but also facilitated the formation of a robust SEI film[23]. While developed new type of modified separators are expected to physically suppress the growth of lithium dendrites. For instance, in situ fabricating a stable tissue-directed/reinforced bifunctional separator/protection film (TBF) on the surface of the Li anode effectively protected lithium from the corrosion of $\mathrm{O}_{2}$, discharge intermediates, $\mathrm{H}_{2} \mathrm{O}$ and electrolyte, and reduce morphology change of the surface of lithium anode[24]. In terms of novel electrode materials/structures, infusion the Li metal into a carbon framework or synthesis of lithium-based composites[25-27], enables to control the growth of lithium dendrites, but also solves the infinite volume change issue of lithium-based electrodes[18, 28]. For instance, Koratkar and co-workers described defectinduced plating of metallic lithium within the interior of a porous graphene network[27]. The network acted as seed points that initiated plating of lithium metal and prevented dendritic growth.

Based on the aforementioned considerations, stable operation of Li metal anodes, no matter inhibit the lithium dendrite growth or controllable side reaction and volume change, is critical for next-generation battery technologies. Thus, in this short perspective article, we briefly review the Li-containing alloys reported in the literatures to stabilize Li metal anodes and propose a few new suggestions for protecting the Li metal by reasonably combining the lithium-containing alloys with other strategies.

\section{Failure Mechanisms of Metallic Lithium Anodes}

Before introducing the practical applications of lithium alloy in present metal lithium batteries, it is necessary to understand the failure mechanisms of lithium anode. Actually, during the past 10 years, deep and fundamental understanding on the failure mechanisms of the Li metal anode has been extensively discussed. No matter in LIBs, Li-S, $\mathrm{Li}_{-} \mathrm{O}_{2}$ or solid-state electrolyte Li-metal batteries, generally, these issues will cause the failure of Li anode[29-31]:

i) Uncontrolled interfacial reactions: the uncontrolled interfacial reaction also called the side reactions that happen on the Li-metal surface with the organic electrolytes. As the high reactivity of Li-metal in the organic electrolyte, it easily appears corrosive reactions to deplete the electrolytes and generate thick SEI layers, which will lead to increasing resistance and low Coulombic efficiency[29].

ii) Uncontrollable Li dendrite growth: the Li dendrites could penetrate through the separator and cause cell short circuit, resulting in a series of safety concerns[32]. Meanwhile, the dendritic Li could also produce so-called "dead Li" via electrical detachment of Li from the current collector; significantly affect the cycle life of the Li-metal battery[32]. And now it is widely accepted that unstable and inhomogeneous SEI films, inhomogeneous electric fields, and inordinate lithium-ion flux are the origination of the dendrite growth $[2$, $18]$.

iii) Infinite relative volume changes: as the "hostless" nature of Li, during repeated stripping/plating process, 
the relative volume change of $\mathrm{Li}$ anode is virtually infinite, which will initiate cracks on the SEI, leading high structural instability for the Li anode[2]. As the specific example illustrated in the previous report[2, 33], a single-sided commercial electrode needs to reach an areal capacity of $3 \mathrm{~mA}^{*} \mathrm{~h}^{*} \mathrm{~cm}^{-2}$, indicating a huge change in thickness of $\sim 14.6 \mu \mathrm{m}$ for Li. In terms of future applications, this value could be even higher, really a formidable challenge on the SEI stability.

\section{How Li-containing alloys solving the present issues?}

The first use of lithium alloys as negative electrodes in commercial batteries to operate at ambient temperatures was the employment of Wood's metal alloys in lithium-conducting button type cells by Matsushita in Japan. Development work on the use of these alloys started in 1983[34, 35], and they became commercially available somewhat later[35]. Since then, researchers not only used the lithium alloys as the anodes to reduce the activity of $\mathrm{Li}$ anode and stabilize it[36], but also developing various kinds of other strategies, i.e, constructing rational design of anode structure (3D hosts and 3D current collectors) [25, 37], suppressing Li dendrite growth via modification of electrolytes, separators and anode interfacial engineering[2, 38], etc.

\section{1 | DIRECTLY USING LITHIUM ALLOYS TO REPLACE METALLIC LITHIUM AS ANODE}

The lithium-free alloy anodes, such as Sn-Sb, Sn-Co, Ni-Sn alloy, etc., without pre-stored lithium, the overall energy density is limited by the low-capacity lithium metal oxide cathodes, while the pure lithium metal anode face its high reactivity and uncontrolled dendrite growth[39]. Li-containing alloy anodes inheriting the desirable properties of alloy anodes and pure Li metal anodes. Lithium alloy anodes for rechargeable ambient temperature lithium batteries have been studied since the early 1970[40, 41]. During the past 40 years, great deals of literatures have been reported using the lithium-containing alloys as the anode materials for lithium ion batteries[18, 30, 32-34, 38, 42-44]. They can effectively reduce Li nucleation overpotential and decrease interfacial resistance, guiding the formation and growth of non-dendritic Li[25]. Among these lithium alloys anode, they can mainly divided into two categories: binary lithium alloys and ternary lithium alloys. And different lithium alloys anodes have their own advantages and disadvantages.

For example, Li-Si alloy anodes exhibit multiple attractive properties: i) fully lithiated $\mathrm{Li}_{x} \mathrm{Si}$ alloy has a sufficiently low potential of around $10 \mathrm{mV}$ versus $\mathrm{Li} / \mathrm{Li}^{+}$to prelithiate all types of anodes including graphite, $\mathrm{Si}, \mathrm{Ge}$ and $\mathrm{Sn}[45]$; ii) due to the super-high capacity of $\mathrm{Si}\left(4200 \mathrm{~mA} \cdot \mathrm{h} \cdot \mathrm{g}^{-1}\right), \mathrm{Li}_{x} \mathrm{Si}$ alloy anode could also illustrate high specific capacity even a small percentage of pre-storing lithium, i.e., $\mathrm{Li}_{4.4} \mathrm{Si}$ shows a capacity of $2000 \mathrm{~mA}^{*} \mathrm{~h}^{*} \mathrm{~g}^{-1}$ [45]. Most of the Li-Si electrodes were obtained by electrochemical lithiation of Si-based electrodes[46-48], which is very difficult to employ for practical application[47]. But recently, there have been reported other two methods to synthesis the Li-Si alloy: one is pressing plus heat-treatment process as shown in Figure 1a[47], another one is ball milling method (Figure 1b) at argon atmosphere[49-51].

Except the $\mathrm{Li}_{x} \mathrm{Si}$ alloy, the lithium alloy anodes of other IVA group elements has also been widely reported, such as Li-Sn and Li-Ge alloy anodes[48, 52-58]. Similar as $\mathrm{Li}_{x} \mathrm{Si}$ alloy, the Li-Sn and Li-Ge alloy anodes also exhibit relative high specific capacity $[48,57]$. While the Li-Sn alloy anode also shows its unique merits, including the fast interdiffusion of $\mathrm{Li}$ in $\mathrm{Sn}$ and the $<500 \mathrm{mV}$ separation between Li-Sn alloy formation and Li plating. Archer's group reported a Li-Sn hybrid battery anodes created by depositing an electrochemically active $\mathrm{Sn}$ on a reactive Li metal electrode by a facile ion-exchange chemistry as shown in Figure 1c, leading to very high exchange currents and stable long-term performance[59]. The Li-Sn anodes were shown to be stable at $3 \mathrm{~mA}^{*} \mathrm{~cm}^{-2}$ and $3 \mathrm{~mA}^{*} \mathrm{~h}^{*} \mathrm{~cm}^{-2}$. While in contrast to $\mathrm{Si}$, Ge has the benefit of forming a minimal amount of native oxide in its outermost layer and the diffusivity of lithium in Ge is 400 times greater than that of lithium in Si at room temperature, but as the high cost of Ge, the Li-Ge alloy anodes have not gained much attention[34]. 
The Li-Al alloy anode showed higher stability in the air, carbonate-based electrolyte and the electrolyte with $\mathrm{LiNO}_{3}$ additive[60, 61]. Also, Al alloying with $\mathrm{Li}$ exhibits much smaller volume change ([?]96\%) compared with other alloy anodes, such as Li-Si (320\%) and Li-Sn (260\%) alloys anode[62]. In addition, Li diffusion coefficient in Li-Al alloy $\left(6.0 \times 10^{-10} \mathrm{~cm}^{2 *} \mathrm{~s}^{-1}\right)$ exceeds that in bulk Li metal $\left(5.69 \times 10^{-11} \mathrm{~cm}^{2 *} \mathrm{~s}^{-1}\right)[63]$. LiB alloy is widely used as anode in thermal battery, which can be regarded as free metal lithium metal filled in the fibrillar network framework of $\mathrm{Li} / \mathrm{B}$ compound $\left(\mathrm{Li}_{7} \mathrm{~B}_{6}\right)[64,65]$, such a porous structure can increase the specific surface area and adjust $\mathrm{Li}$ ions even distribution. As the discharge potential of $\mathrm{Li}_{7} \mathrm{~B}_{6}$ is over 0.4 $\mathrm{V}$ (vs. $\mathrm{Li} / \mathrm{Li}^{+}$), thus when Li-B alloy used in metal lithium battery, its free metal lithium participates in electrochemical reaction preferentially[64]. Additionally, $\mathrm{Li}_{7} \mathrm{~B}_{6}$ has a good conductivity $\left(1.43 \times 10^{3-1 *} \mathrm{~cm}^{-1}\right)$ and a high $\mathrm{Li}$ ion diffusion rate comparative to metallic lithium[64]. Thus, in 2013, Yang's group firstly investigated Li-B alloy as anode for lithium/sulfur battery[64]. It is because of the above advantages, Li-B alloy has better behaviors in restraining the formation of dendritic lithium, reducing the interface impedance of electrode and improving the cycle performance of the battery. For Li-In alloy electrode, Archer's group found the interfacial of the resultant Li-In alloy electrode was significant lower than that of the pristine $\mathrm{Li}$ metal, which allowed Li ions diffused along the surface to form uniform deposit on the hybrid electrode[66]. As a result of the enhanced interfacial ion transport mechanism, compact and uniform electrodeposition for the Li-In alloy anode at long time scales has been realized. And the Li-In hybrid anodes to full cells employing high-loading commercial cathodes (LTO and nickel manganese cobalt oxide) showed that the electrodes can be cycled stably for over 250 cycles with close to $90 \%$ capacity retention. Recently, Adelhelm investigated the different $\mathrm{In} / \mathrm{Li}$ ratio on the performances of Li-In anode[67]. The right In/Li ratio, i.e. 1.27:1, enabled stable lithium insertion/deinsertion in symmetrical cells for at least 100 cycles; while too much lithium in the electrode leaded to a drop in redox potential combined with a rapid build-up of interface resistance.

Compared with the group IVA and group IIIA lithium alloys, even as early as 1970 s, the $\mathrm{Li}_{3} \mathrm{Sb}$ and $\mathrm{Li}_{3} \mathrm{Bi}$ alloy anodes have also been investigated in metal lithium batteries[68, 69], group VA lithium alloys directly used as anodes in metal lithium batteries are not too many[43, 70-72]. That mainly because the higher toxicity of some VA elements, such as $\mathrm{Sb}$ and $\mathrm{As}$, and the smaller gravimetric capacity of $\mathrm{Bi}[34]$. In addition, the synthesis conditions of VA lithium alloys are higher demanding, taking the Li-Sb alloy, except complex prelithiation with $\mathrm{Sb}$, another method is prepared by electrolysis of the molten $\mathrm{LiCl}-\mathrm{KCl}$ eutectic mixture with a liquid antimony cathode at high-temperature[71]. In contrast, the Bi/Sb-based nanocomposites and $\mathrm{Bi} / \mathrm{Sb}$-based intermetallics could be easily and large-scale production, as well as demonstrated good electrochemical performances when used as anode materials for LIBs[34]. Therefore, during the past 40 years, there has been no significant development of the group VA lithium alloys as the anodes in metal lithium batteries.

Beside these three group elements, some other elements such as $\mathrm{Na}[73,74], \mathrm{Mg}[75-80], \mathrm{Zn}[81,82], \operatorname{In}[66$, 67], $\mathrm{Ag}[83,84], \mathrm{Au}[84]$, etc., can alloy with $\mathrm{Li}$ as well. And recently, these lithium-alloys used as the anode materials in lithium metal batteries have gained increasing attentions.

$\mathrm{Li}-\mathrm{Na}$ alloy can supply $\mathrm{Li}^{+}$on stripping and thus ensure the electrostatic shield effect of $\mathrm{Li}^{+}{ }^{[85]}$. And $\mathrm{Li}-\mathrm{Na}$ alloy would not sacrifice the specific capacity of the anode because $\mathrm{Li}$ and $\mathrm{Na}$ metals exhibit similar reaction activities as well as electrolyte compatibility of $\mathrm{Li}^{+}$and $\mathrm{Na}^{+}{ }^{[85]}$. However, developing a Li-Na alloy anode might be difficult because of volume expansion[73, 74, 85], which causes SEI damage, large internal resistance and low Coulombic efficiency. Recently, Zhang's group reported a $\mathrm{Li}-\mathrm{Na}$ alloy anode used in Li$\mathrm{O}_{2}$ batteries[85]. By optimizing the Na/Li value of the alloy, a dendrite-suppressed, oxidation-resistant and crack-free Li-Na alloy anode could be obtained[85], thus realizing an alloy anode with a long cycle life.

The Li-Mg alloy is advantageous because of the generally lower reactivity of Li (or relatively low Li activity), the large solid solution range, the mechanical integrity of $\mathrm{Mg}$ framework and a relatively large diffusion coefficient of $\mathrm{Li}$ in $\mathrm{Mg}\left(10^{-7} \mathrm{~cm}^{2 *} \mathrm{~s}^{-1}\right.$ for the $\mathrm{Li}-\mathrm{Mg}$ alloy produced by vapor deposition) $[75,77-79,86] . \mathrm{Mg}$ alloying can increase lithium utilization, when no external pressure is applied while pure lithium metal is superior for setups that allow stack pressures in the MPa range[75]. And appropriate amount $\mathrm{Mg}$, i.e, 10 at\%, introducing into Li metal anode can also effectively prevent contact loss[75]. Due to these various 
advantages, recently, Gao's group reported Li-Mg alloy as an anode for Li-S batteries[76]. Compared to the metallic $\mathrm{Li}$ anode, the $\mathrm{Li}-\mathrm{Mg}$ alloy showed remarkable improvement on stability at the surface and in the bulk during cycling as shown in Figure 1d and 1e. And they also found after Li stripping, a conducting Li-poor Li-Mg alloy matrix was formed, facilitating subsequent plating and diffusion of Li ions.
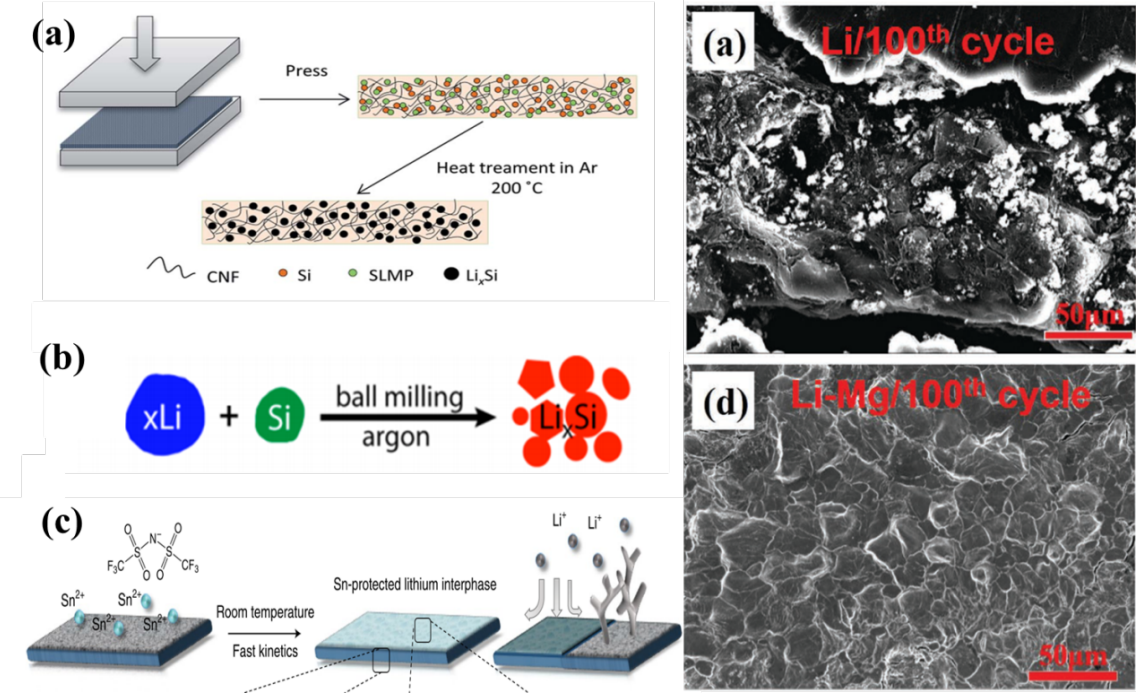

Figure 1 (a) Illustration of the preparation process of carbon-supported Li-Si alloy electrodes. (Reproduced from ref.[47], with permission from Copyright (C) 2018 The Royal Society of Chemistry.) (b) Scheme illustrating the high-energy ball-milling process using Li grains and Si powders as precursors. (Reproduced from ref.[49], with permission from Copyright (C) 2014 American Chemical Society.) (c) Hybrid anodes based on facile and fast Sn deposition on reactive metals produced by ion exchange in a common used aprotic liquid lithium electrolyte, $1 \mathrm{M} \mathrm{LiPF}_{6}$ in an ethylene carbonate-dimethyl carbonate (EC/DMC) solvent blend containing a second salt. (Reproduced from ref.[59], with permission from Copyright (C) 2019 Elsevier Ltd..) Surface morphology and elemental distribution of the cycled (d) Li metal and (e) Li-Mg alloy anode retrieved from the cells after 100 cycles. (Reproduced from ref.[76], with permission from Copyright (C) 2019 WILEY-VCH.)

Even the theoretical of Li-Zn alloy is not as high as Li-Si, Li-Sn, Li-Ge, Li-Sb alloys, etc., the volume expansion of Li-Zn alloys is not obvious when used in Li storage[82]. Chen et al. reported a Li-Zn alloy synthesized by depositing $\mathrm{Li}$ on the $\mathrm{Zn}$ substrate precursor at a constant current density of $0.05 \mathrm{~mA} \cdot \mathrm{cm}^{-2}$ until the potential reached $0 \mathrm{~V}\left(\mathrm{vs} . \mathrm{Li} / \mathrm{Li}^{+}\right)$[82]. The efficiency of $\mathrm{Li}$ deposition/stripping on the $\mathrm{Li}-\mathrm{Zn}$ alloy anode remained high at $96.7 \%$ after 400 cycles at a current density of $0.1 \mathrm{~mA}^{*} \mathrm{~cm}^{-2}$ and 250 cycles at the current density of $0.2 \mathrm{~mA}^{*} \mathrm{~cm}^{-2}$.

Different from the Si and $\mathrm{Sn}$ that experienced reconstitution reaction with lithium to form alloys, $\mathrm{Au}$ and $\mathrm{Ag}$, as two typical noble metals, involve solid-solution reaction with $\mathrm{Li}$ to form $\mathrm{LiAu}_{x}$ and $\mathrm{LiAg}_{x}$ alloys $[83$, 84]. The solid-solution reaction involves much less structure change than its counterpart (e.g. Si and Sn) in the lithiation-delithiation process, therefore can take place with a low charge-discharge voltage hysteresis at a potential that is very close to that of $\mathrm{Li} / \mathrm{Li}^{+}$redox couple and eliminate the nucleation barriers[83]. For example, in 2016, Cui's group has found $\mathrm{Au}, \mathrm{Ag}, \mathrm{Zn}$ and $\mathrm{Mg}$ with good solubility in Li, once fully lithiated, exhibited zero overpotential during deposition of $\mathrm{Li}$ as shown in Figure 2a[84]. For materials $\mathrm{Al}$ and $\mathrm{Pt}$ have relatively small solubility in Li metal and show small but observable overpotential for Li nucleation $(5 \mathrm{mV}$ for $\mathrm{Al}, 8 \mathrm{mV}$ for $\mathrm{Pt}$ ); For materials showing no solubility $(\mathrm{Cu}, \mathrm{Ni}, \mathrm{C}, \mathrm{Sn}, \mathrm{Si}$ ) in lithium were also tested, as shown in Figure 2b, all five materials show a clear overpotential for Li metal nucleation. According to this vital findings, they designed Au nano particles distributed inside the hollow carbon spheres to selectively 
nucleate and grow Li metal inside carbon nanoshells during electrochemical deposition, as shown in Figure 2c.
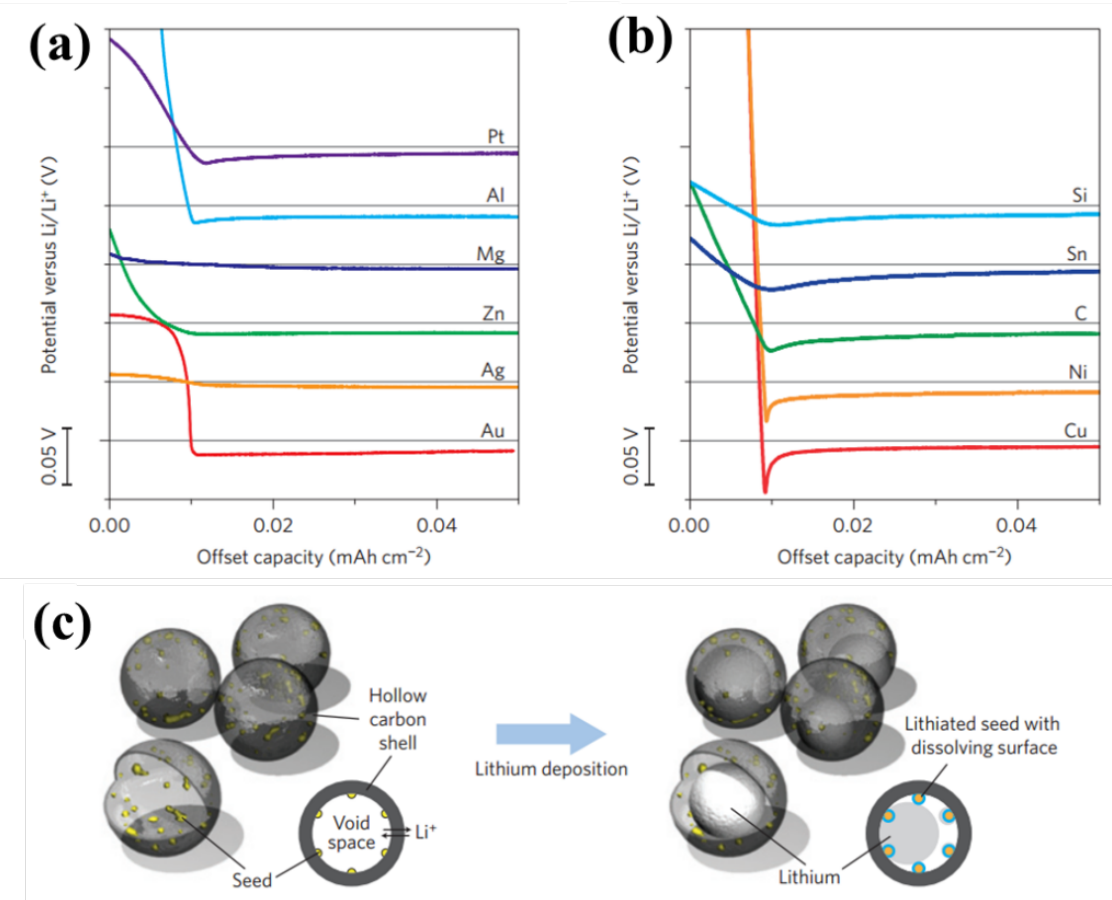

Figure 2 (a) Voltage profiles of various materials with some solubility in Li during Li deposition at a current density of $10 \mu \mathrm{A} \cdot \mathrm{cm}^{-2}$. To enhance the comparison, the curves are shifted horizontally according to the onset of lithium nucleation and vertically with a constant shift of $0.05 \mathrm{~V}$. The scale of the y-axis is indicated by the bar in the bottom left. (b) Shifted voltage profiles of various materials with negligible solubility in Li during $\mathrm{Li}$ deposition at a current density of $10 \mu \mathrm{A} \cdot \mathrm{cm}^{-2}$. The horizontal grey lines show $0 \mathrm{~V}$ versus $\mathrm{Li}$ in a and $\mathrm{b}$. (c) Schematic of Li metal nanocapsules design. Au NPs are loaded inside hollow carbon spheres, where a large void space is reserved for $\mathrm{Li}$ metal. $\mathrm{Li}$ is expected to nucleate from the $\mathrm{Au}$ seed. Carbon shells provide both confinement and protection of the Li metal, as well as conduction channels for both electrons and $\mathrm{Li}$ metal. (Reproduced from ref.[84], with permission from Copyright (c) 2016 Macmillan Publishers Limited.)

Even the binary Li-containing alloy systems, such as Li-Al, Li-Si, Li-Sn, Li-Ge, Li-Sb, etc., possessed a particularly larger capacity than the commercialized graphite, but these binary lithium alloy electrodes usually suffered rather poor cycle performance as catastrophic structural changes with large volume expansion[87]. To overcome this poor reversibility in such intermetallic lithium alloy electrodes, the ternary Li-containing alloy compounds have been investigated. For example, Hashimoto et al. reported $\mathrm{Li}_{4.4} \mathrm{Ge}_{x} \mathrm{Si}_{1-x}$ alloys synthesized by mechanically milling process[88]. The $\mathrm{Li}_{4.4} \mathrm{Ge}_{x} \mathrm{Si}_{1-x}$ alloys formed a solid solution over the whole composition range of $0[?] x$ [?]1. Among the obtained alloys, the $\mathrm{Li}_{4.4} \mathrm{Ge}_{0.67} \mathrm{Si}_{0.33}$ alloy showed the largest specific capacity of $190 \mathrm{~mA}^{*} \mathrm{~h}^{*} \mathrm{~g}^{-1}$ and good charge-discharge reversibility. Yang et al. reported a ternary $\mathrm{Li}_{2.6} \mathrm{BMg}_{0.05}$ alloy as an alternative anode to metallic lithium[89]. The pristine $\mathrm{Li}_{2.6} \mathrm{BMg}_{0.05}$ consists of rhombohedral $\mathrm{Li}_{5} \mathrm{~B}_{4}$, cubic lithium and $\mathrm{Li}_{3} \mathrm{Mg}_{7}$. Therefore, it owns both the advantages of $\mathrm{Li}-\mathrm{Mg}$ alloy and $\mathrm{Li}-\mathrm{B}$ alloy, which $\mathrm{Li}-\mathrm{Mg}$ binary alloy with good solid solution over a wide range of composition without phase transformation, provides high specific capacity and Li-B alloy with porous structure can increase the specific surface area and its very negative potential close to pure lithium (ca. $20 \mathrm{mV}$ vs. $\mathrm{Li} / \mathrm{Li}^{+}$) provides a basic condition for the high energy density. Pan et al, reported $\mathrm{Li}_{2} \mathrm{MgSi}$ as a novel anode for Li-ion batteries[90]. Directly using $\mathrm{Li}_{2} \mathrm{MgSi}$ as an anode material can prevent the dissociation of metallic $\mathrm{Mg}$ and/or 
$\mathrm{Li}-\mathrm{Mg}$ alloy from $\mathrm{Mg}_{2} \mathrm{Si}$. And the pre-lithiated $\mathrm{Li}_{2} \mathrm{MgSi}$ is likely to reduce the stress/strain during delithiation/lithiation. In addition, by constructing a ternary alloy that contain inactive materials, such as LiCuSn and $\mathrm{LiCuSb}$ alloy[87, 91], the volume variation of active elements could be buffered by inactive medium when active elements are dispersed uniformly in situ or ex situ into the matrix of inactive components at nanoscale, as in the cases of active/inactive composites and intermetallic compounds[92].

Compared to plenty of binary Li-containing alloys anodes, there are few reports on multi-component lithium alloy anodes[36, 87-91, 93-97]. One reason is the much lower specific capacity of the ternary lithium alloys, i.e, $\mathrm{Li}_{4.4} \mathrm{Ge}_{0.67} \mathrm{Si}_{0.33}[88], \mathrm{Li}_{0.25} \mathrm{CuP}[96]$, etc., compared to the binary lithium alloys; another most possible reason is rather difficult to prepare high-purity multi-component lithium alloy[90], as a result, the theoretical capacities are hard to calculate as well as the electrochemical mechanisms are difficult fully understood[87].

Table 1 The typical lithium alloys anodes employed in lithium ion, Li-S and $\mathrm{Li}^{-} \mathrm{O}_{2}$ batteries as well as their advantages and disadvantages.

\begin{tabular}{|c|c|c|c|c|}
\hline Categories & $\begin{array}{l}\text { Synthesized } \\
\text { methods }\end{array}$ & Advantages & Disadvantages & References \\
\hline $\mathrm{Li}-\mathrm{Si}$ & $\begin{array}{l}\text { fusion reaction } \\
\text { method; } \\
\text { electrochemical } \\
\text { lithiation method; } \\
\text { mechanical ball } \\
\text { milling method }\end{array}$ & $\begin{array}{l}\text { superior high } \\
\text { gravimetric capacity } \\
\left(\mathrm{Li}_{21} \mathrm{Si}_{5}: 1967\right. \\
\left.\mathrm{mA} \cdot \mathrm{h} \cdot \mathrm{g}^{-1}\right) ; \text { low } \\
\text { potential of around } \\
10 \mathrm{mV} \text { versus } \\
\mathrm{Li} / \mathrm{Li}^{+}\end{array}$ & $\begin{array}{l}\text { great volume } \\
\text { expansion; poor } \\
\text { reversibility; } \\
\text { difficult to realize } \\
\text { electrochemical } \\
\text { lithiation into } \\
\text { practical } \\
\text { application; high } \\
\text { overpotential for Li } \\
\text { metal nucleation }\end{array}$ & $\begin{array}{l}{[39][45][46][47]} \\
{[48][49][50][51]} \\
{[84]}\end{array}$ \\
\hline Li-Sn & $\begin{array}{l}\text { fusion reaction } \\
\text { method; } \\
\text { electrodeposition } \\
\text { method; surface } \\
\text { chemical treatment } \\
\text { method }\end{array}$ & $\begin{array}{l}\text { high gravimetric } \\
\text { capacity }\left(\mathrm{Li}_{22} \mathrm{Sn}_{5} \text { : }\right. \\
\left.991 \mathrm{~mA} \cdot \mathrm{h} \cdot \mathrm{g}^{-1}\right) ; \\
\text { strong affinity } \\
\text { towards metallic Li; } \\
\text { small interface } \\
\text { impedance and fast } \\
\text { lithium ion diffusion }\end{array}$ & $\begin{array}{l}\text { great volume } \\
\text { expansion; poor } \\
\text { reversibility; high } \\
\text { overpotential for Li } \\
\text { metal nucleation }\end{array}$ & $\begin{array}{l}{[39][52][53][54]} \\
{[55][56][57][59]} \\
{[84]}\end{array}$ \\
\hline Li-Ge & $\begin{array}{l}\text { electrochemical } \\
\text { lithiation method }\end{array}$ & $\begin{array}{l}\text { high gravimetric } \\
\text { capacity } \\
\left(\mathrm{Li}_{17} \mathrm{Ge}_{4}: 1568\right. \\
\left.\mathrm{mA} \cdot \mathrm{h} \cdot \mathrm{g}^{-1}\right) \text {; faster } \\
\text { lithium diffusivity } \\
\text { at room } \\
\text { temperature }\end{array}$ & $\begin{array}{l}\text { great volume } \\
\text { expansion, poor } \\
\text { reversibility, high } \\
\text { cost of Ge }\end{array}$ & {$[48]$} \\
\hline $\mathrm{Li}-\mathrm{B}$ & $\begin{array}{l}\text { fusion reaction } \\
\text { method }\end{array}$ & $\begin{array}{l}\text { Porous structure for } \\
\text { accommodating Li } \\
\text { deposition; good } \\
\text { conductivity } \\
\left(1.43 \times 10^{3}-1 * \mathrm{~cm}^{-1}\right) \text {; } \\
\text { a high Li ion } \\
\text { diffusion rate }\end{array}$ & $\begin{array}{l}\text { easily porosity } \\
\text { blocking and } \\
\text { structure collapse, } \\
\text { low hardness }\end{array}$ & {$[64][65]$} \\
\hline
\end{tabular}




\section{Li-Al}

Li-In

Li-Bi

Li-Sb

$\mathrm{Li}-\mathrm{Na}$ magnetron sputtering; fusion reaction method; electrochemical lithiation method

electroless plating method; electrochemical lithiation method

electrochemical lithiation method

electrolysis of liquid antimony with melting salt; electrochemical lithiation method

fusion reaction method higher stability in the air and electrolyte; smaller volume change; lighter; working in high temperature (i.e. $450{ }^{\circ} \mathrm{C}$ )

high

electropositivity of lithium relative to indium; a constant redox potential of about $0.6 \mathrm{~V}$ vs. $\mathrm{Li}^{+} / \mathrm{Li}(0.5 \mathrm{~V}$ at $\left.415{ }^{\circ} \mathrm{C}\right)$; minimal capacity fade high volumetric capacity $\left(\mathrm{LiB}_{3}\right.$ : $1760 \mathrm{~mA} \cdot \mathrm{h} \cdot \mathrm{cm}^{-3}$ ); working in high temperature (> $380 \operatorname{deg}$ )

high volumetric capacity ( $\mathrm{Li}_{3} \mathrm{Sb}: 1890$ $\mathrm{mA} \cdot \mathrm{h} \cdot \mathrm{cm}^{-3}$ ); working in high temperature $(>350$ $\operatorname{deg} \mathrm{C})$

not sacrifice the specific capacity because $\mathrm{Li}$ and $\mathrm{Na}$ metals exhibit similar reaction activities; good electrostatic shield effect moderate gravimetric capacity (550 $\left.\mathrm{mA} \cdot \mathrm{h} \cdot \mathrm{g}^{-1}\right)$; a very narrow range of composition;

phase transformations during cycling, easily disintegrate or degrade; observable overpotential for $\mathrm{Li}$ nucleation high cost

low gravimetric capacity $\left(\mathrm{LiB}_{3}\right.$ : $386 \mathrm{~mA} \cdot \mathrm{h} \cdot \mathrm{g}^{-1}$ )

great volume expansion, poor reversibility; toxic; complex synthesis method; moderate gravimetric capacity ( $\mathrm{Li}_{3} \mathrm{Sb}: 660$ $\mathrm{mA} \cdot \mathrm{h} \cdot \mathrm{g}^{-1}$ ) great volume expansion; high reactivity in electrolyte; [66] [67]

[39] [42] [58] [60]

[61] [62] [63] [84]

[34] [68] [69]

[43] [34] [68] [69]

[71]

[73] [74] [85] 


\begin{tabular}{|c|c|c|c|c|}
\hline $\mathrm{Li}-\mathrm{Mg}$ & $\begin{array}{l}\text { fusion reaction } \\
\text { method }\end{array}$ & $\begin{array}{l}\text { high Li-ion } \\
\text { diffusion } \\
\text { coefficient; high } \\
\text { gravimetric } \\
\text { capacity ( } 2690 \\
\mathrm{~mA} \cdot \mathrm{h}^{-1} \text { for the } \\
\mathrm{Mg}-70 \mathrm{wt} \% \mathrm{Li} \\
\text { alloy); lighter; } \\
\text { zero overpotential }\end{array}$ & $\begin{array}{l}\text { covered with an } \\
\text { oxide layer } \\
\text { resulting in poor } \\
\text { Li kinetic } \\
\text { behaviors }\end{array}$ & $\begin{array}{l}{[75][76][77][78]} \\
{[79][80][84]}\end{array}$ \\
\hline Li-Zn & $\begin{array}{l}\text { electrochemical } \\
\text { deposition } \\
\text { method; fusion } \\
\text { reaction method }\end{array}$ & $\begin{array}{l}\text { smaller volume } \\
\text { expansion; good } \\
\text { lithiophilic } \\
\text { property to adjust } \\
\text { even Li } \\
\text { deposition; } \\
\text { eliminating } \\
\text { nucleation } \\
\text { barriers }\end{array}$ & $\begin{array}{l}\text { low gravimetric } \\
\text { capacity }(355 \\
\left.\mathrm{mA} \cdot \mathrm{h} \cdot \mathrm{g}^{-1}\right)\end{array}$ & $\begin{array}{l}{[81][82][83][84]} \\
{[98]}\end{array}$ \\
\hline $\mathrm{Li}-\mathrm{Au}$ & $\begin{array}{l}\text { electrochemical } \\
\text { lithiation method }\end{array}$ & $\begin{array}{l}\text { less structure } \\
\text { change; zero } \\
\text { overpotential; } \\
\text { eliminating the } \\
\text { nucleation } \\
\text { barriers }\end{array}$ & high cost & {$[84]$} \\
\hline Li-Ag & $\begin{array}{l}\text { electrochemical } \\
\text { lithiation method; } \\
\text { fusion reaction } \\
\text { method }\end{array}$ & $\begin{array}{l}\text { less structure } \\
\text { change; zero } \\
\text { overpotential; } \\
\text { eliminating the } \\
\text { nucleation } \\
\text { barriers }\end{array}$ & high cost & [99] [83] \\
\hline $\mathrm{Li}_{x} \mathrm{CuP}$ & $\begin{array}{l}\text { fusion reaction } \\
\text { method }\end{array}$ & $\begin{array}{l}\text { good cycling } \\
\text { stability }\end{array}$ & $\begin{array}{l}\text { low gravimetric } \\
\text { capacity } \\
\left(\mathrm{Li}_{0.25} \mathrm{CuP}: 430\right. \\
\left.\mathrm{mA} \cdot \mathrm{h} \cdot \mathrm{g}^{-1}\right) ; \\
\text { complex } \\
\text { synthesize } \\
\text { method: } \mathrm{N}_{2} \text { flow } \\
\text { at } 780{ }^{\circ} \mathrm{C} \text { for } 5 \\
\text { days }\end{array}$ & {$[96]$} \\
\hline $\mathrm{Li}_{4.4} \mathrm{Ge}_{x} \mathrm{Si}_{1-x}$ & $\begin{array}{l}\text { ball-milling } \\
\text { method }\end{array}$ & $\begin{array}{l}\text { Increasing lithium } \\
\text { ions } \\
\text { accommodation } \\
\text { in the alloy, good } \\
\text { charge-discharge } \\
\text { reversibility }\end{array}$ & $\begin{array}{l}\text { low gravimetric } \\
\text { capacity } \\
\left(\mathrm{Li}_{4.4} \mathrm{Ge}_{0.67} \mathrm{Si}_{0.33} \text { : }\right. \\
\left.190 \mathrm{~mA} \cdot \mathrm{h} \cdot \mathrm{g}^{-1}\right)\end{array}$ & [88] \\
\hline $\mathrm{Li}-\mathrm{Cu}-\mathrm{Sb}$ & $\begin{array}{l}\text { ball milling method, } \\
\text { electrochemical } \\
\text { lithiation method }\end{array}$ & $\begin{array}{l}\text { good cycling } \\
\text { stability; good } \\
\text { electronic } \\
\text { conductivity }\end{array}$ & $\begin{array}{l}\text { low gravimetric } \\
\text { capacity }\left(\mathrm{Li}_{2} \mathrm{CuSb} \text { : }\right. \\
\left.290 \mathrm{~mA} \cdot \mathrm{h} \cdot \mathrm{g}^{-1}\right)\end{array}$ & [87] [36] \\
\hline
\end{tabular}




\begin{tabular}{|c|c|c|c|c|}
\hline $\mathrm{LiAl}_{1-x} \mathrm{Zn}_{x}$ & $\begin{array}{l}\text { fusion reaction } \\
\text { method }\end{array}$ & $\begin{array}{l}\text { high theoretical } \\
\text { capacities }\end{array}$ & $\begin{array}{l}\text { complex } \\
\text { synthesize } \\
\text { condition: Ar } \\
\text { atmosphere and } \\
\text { very high } \\
\text { temperature }(900 \\
\left.{ }^{\circ} \mathrm{C}\right)\end{array}$ & {$[95]$} \\
\hline $\mathrm{Li}_{2} \mathrm{MgSi}$ & $\begin{array}{l}\text { ball-milling }+ \\
\text { annealing method }\end{array}$ & $\begin{array}{l}\text { prevent the } \\
\text { dissociation of } \\
\mathrm{Li}-\mathrm{Mg} \text { alloy; } \\
\text { reduce the } \\
\text { stress/strain } \\
\text { during delithia- } \\
\text { tion/lithiation; } \\
\text { high capacity } \\
\left(807.8 \mathrm{~mA} \cdot \mathrm{h}^{-1} \mathrm{~g}^{-1}\right)\end{array}$ & $\begin{array}{l}\text { complex } \\
\text { synthesize } \\
\text { method: Ar } \\
\text { atmosphere, } \\
\text { vacuum reaction } \\
\text { at high } \\
\text { temperature; } \\
\text { difficult to } \\
\text { prepare } \\
\text { high-purity }\end{array}$ & {$[90]$} \\
\hline $\mathrm{Li}_{x} \mathrm{Cu}_{6} \mathrm{Sn}_{5}$ & $\begin{array}{l}\text { electrochemical } \\
\text { lithiation method }\end{array}$ & $\begin{array}{l}\text { small irreversible } \\
\text { capacities; high } \\
\text { volumetric } \\
\text { capacity }(1656 \\
\left.\mathrm{mA} \cdot \mathrm{h} \cdot \mathrm{ml}^{-1}\right)\end{array}$ & $\begin{array}{l}\text { low gravimetric } \\
\text { capacity } \\
\left(\mathrm{Li}_{13} \mathrm{Cu}_{6} \mathrm{Sn}_{5}: 358\right. \\
\left.\mathrm{mA} \cdot \mathrm{h} \cdot \mathrm{g}^{-1}\right)\end{array}$ & {$[91]$} \\
\hline $\mathrm{Li}_{x} \operatorname{InSb}$ & $\begin{array}{l}\text { ball milling }+ \\
\text { electrochemical } \\
\text { lithiation method }\end{array}$ & $\begin{array}{l}\text { good reversibility, } \\
\text { stable during } \\
\text { lithiation; very } \\
\text { small volume } \\
\text { changes }\end{array}$ & $\begin{array}{l}\text { Low specific } \\
\text { capacity ( } \mathrm{LiInSb} \text {, } \\
\mathrm{Li}_{2} \mathrm{InSb} \text {, and } \\
\mathrm{Li}_{3} \mathrm{InSb} \text {, are } 113 \text {, } \\
227, \text { and } 340 \\
\mathrm{~mA} \cdot \mathrm{h} \cdot \mathrm{g}^{-1} \text { ) }\end{array}$ & {$[97]$} \\
\hline Li-B-Mg & $\begin{array}{l}\text { fusion reaction } \\
\text { method }\end{array}$ & $\begin{array}{l}\text { Porous structure; } \\
\text { very negative } \\
\text { potential close to } \\
\text { pure lithium; } \\
\text { good strength and } \\
\text { hardness, high } \\
\text { capacity } \\
\left(\mathrm{Li}_{2.6} \mathrm{BMg}\right. \\
\left.1181.6 \mathrm{~mA} \cdot \mathrm{h}_{0 .} \cdot \mathrm{g}^{-1}\right)\end{array}$ & $\begin{array}{l}\text { complex } \\
\text { synthesize } \\
\text { method: Ar } \\
\text { atmosphere, } \\
\text { heating at high } \\
\text { temperature }\end{array}$ & {$[89][93]$} \\
\hline
\end{tabular}

To summary, table 1 has make conclusions about the various kinds of binary and multi-component Licontaining alloys anodes as well as their advantages and disadvantages. As can be seen, there are not perfect lithium alloys used as the anodes. It is impossible to solve the problem simply by replacing lithium metal with lithium alloys. Thus, combining the lithium alloys with other materials, such as graphene, polymers, etc., to overcome the weak links of lithium alloys have been proposed.

In order to solve some of the lithium alloys instability in air, Cui's group developed densely packed Li $\mathrm{M}_{x}$ $(\mathrm{M}=\mathrm{Si}$, Sn, or $\mathrm{Al})$ nanoparticles encapsulated by large graphene sheets as shown in Figure 3a[39]. With the protection of graphene sheets, the large and freestanding $\mathrm{Li}_{x} \mathrm{M}$ /graphene foils are stable in different air conditions. Among the representative $\mathrm{Li}_{x} \mathrm{Si} /$ graphene foil maintained a stable structure and cyclability in half cells (400 cycles with $98 \%$ capacity retention). And when paired with high-capacity Li-free $\mathrm{V}_{2} \mathrm{O}_{5}$ and sulfur cathodes, stable full-cell cycling could also achieve. And the alloy electrodes have a high reduction potential, leading to low energy density. To overcome drastic volume variation during Li insertion/extraction 
cycles, except to prepare superfine alloy particles that have small absolute volume variation or constructing ternary alloy that contain an inactive metal to inhibit the great volume expansion, but also can encapsulate the lithium alloys in the flexible and elastic polymer matrix. For example, Cui's group reported a polymer supported Li-Zn alloy structure as shown in Figure 3b[100]. They used the ALD method to deposit the ZnO on the polymide (PI) fiber. The core-shell PI-ZnO matrix was put into contact with molten Li, ZnO reacted with molten $\mathrm{Li}$ to form Li-Zn alloy and simultaneously extra Li can be drawn into the polymer matrix, affording a Li-coated PI electrode. Thanks to the polymer shell, the lithium alloys crack and pulverization can be alleviated.

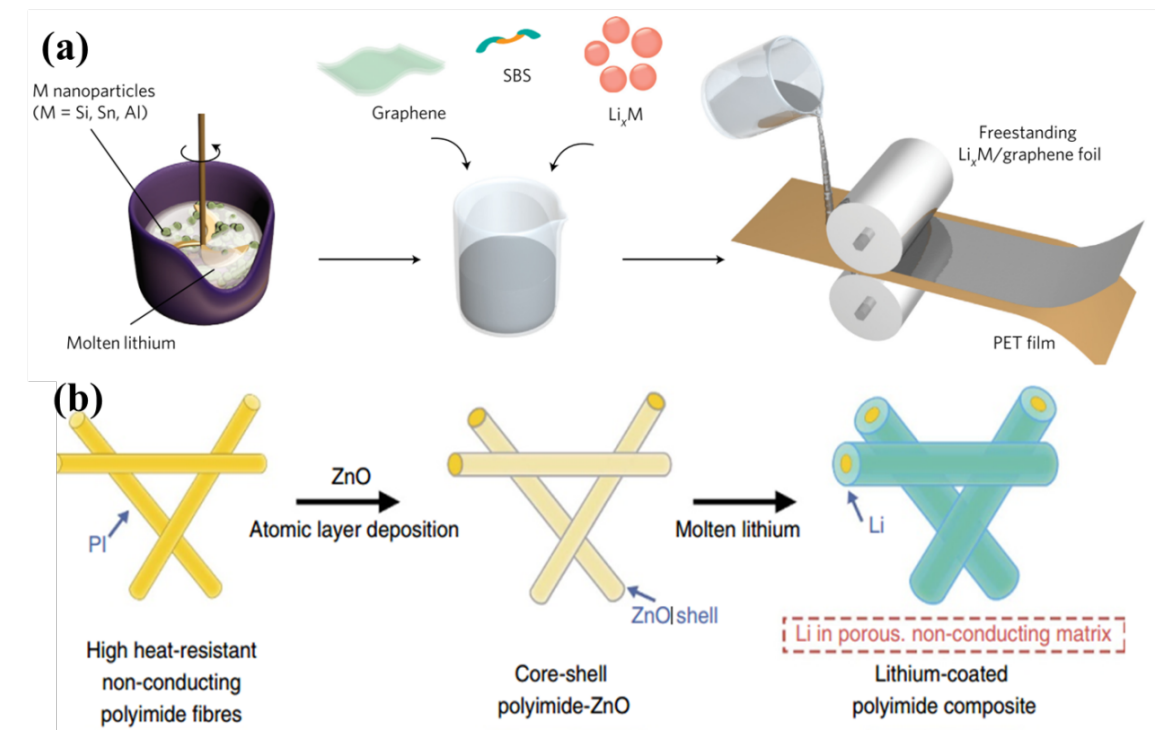

Figure 3 (a) Schematic of the microstructure and fabrication process of the $\mathrm{Li}_{x} \mathrm{M} /$ graphene foils. (Reproduced from ref.[39], with permission from Copyright (C) 2017 Macmillan Publishers Limited, part of Springer Nature.) (b) Schematic representation of 3D Li-coated PI alloy electrode. (Reproduced from ref.[100], with permission from Copyright (C) 2016 Springer Nature.)

\section{2 | Lithium alloys matrix Equations}

By confining $\mathrm{Li}$ in a 3D structure, the infinite volume change during cycling could be eliminated[101]. Furthermore, the high surface area provided by 3D structures can further lower the localized current density and enable a more stable plating/stripping process[26]. Even confining the lithium metal in 3D carbon materials is a more common strategy, there are still some pioneering works on using the 3D lithium alloys matrix to host the lithium metal[26, 37, 102].

In 2014, Zhang's group first employed a 3D lithium alloys $\left(\mathrm{Li}_{7} \mathrm{~B}_{6}\right)$ fibrous matrix for ultra-stable lithiumsulfur batteries[37]. The 3D nanostructured $\mathrm{Li}_{7} \mathrm{~B}_{6}$ framework with high surface area and enough volume space, could not only decrease the areal current density, but also adequately accommodate the electrolyte and re-deposited $\mathrm{Li}$ to stabilize the concentration of $\mathrm{Li}$ ions. By employing this $\mathrm{Li}_{\mathrm{Li}} \mathrm{Li}_{7} \mathrm{~B} 6$ anode, the Li-S batteries could stability cycle to 2000 cycles. Recently, Yan and his co-workers reported a 3D Mg doped $\mathrm{LiB}$ skeleton for hosting the metallic lithium and inhibiting the lithium dendrite growth as shown in Figure $4 \mathrm{a}$ and $4 \mathrm{~b}$ [102]. The 3D LiB skeleton could significantly reduce volume variation during Li electrochemical dissolution/deposition process. Its superior lithiophilic and conductive characteristics could also contribute to the reduction of the local current density and homogenization of incoming $\mathrm{Li}^{+}$flux. More importantly, Yan et al., used the Density Functional Theory (DFT) calculation proved the doping of Mg element to the 3D $\mathrm{LiB}$ skeleton could enhance the adsorption energy of Li. And the remaining Li-deficient Li-Mg alloy forming 
after Li stripped can help connect LiB fibers to stabilize the whole skeleton and lower interfacial resistance, which could effectively inhibit the lithium dendrite growth as shown in Figure 4c and 4d.
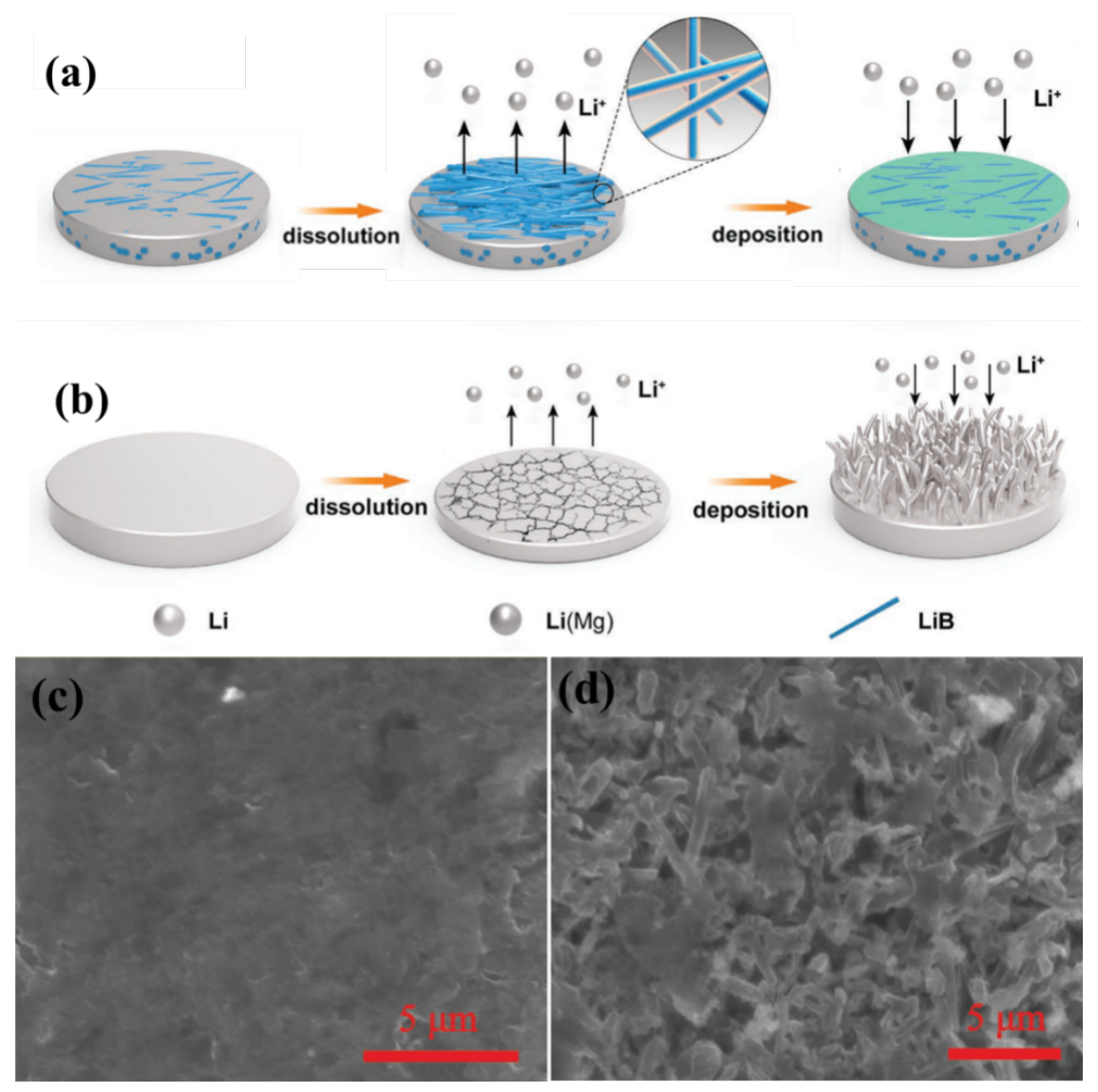

Figure 4 The Li electrodissolution/electrodeposition process of (a) Li-B-Mg composite and (b) pure Li foil. The SEM pictures of the Li-B-Mg composite (c) and the pure Li foil (d) after cycling 100 cycles under 2 $\mathrm{mA} \cdot \mathrm{cm}^{-2}$. (Reproduced from ref. [102], with permission from Copyright (c) 2020 The Authors. Published by WILEY-VCH.)

Additionally, constructing a 3D lithium alloy-based composites to deposit lithium has been developed. For example, our group developed a 3D silver nanowire (AgNW) and graphene-based hierarchical host (3DAGBN)[99]. Due to the Li ions will be favorably reduced on the surface of AgNWs to form Li-Ag alloys and induce the Li depositing on the AgNW as well as the high electrical conductivity of the continuous AgNW nanonetwork can guarantee a fast and uniform electron transportation throughout the entire 3D host with low overpotential. Therefore, the Li deposition can be directed within the entire scaffold (Figure 5a) to form a smooth Li layer covering the AgNW nanonetwork after $1 \mathrm{~mA}^{*} \mathrm{~h}^{*} \mathrm{~cm}^{-2}$ plating as shown in Figure $5 \mathrm{~b}$ and c. Yang's group first synthesized a 3D metal-organic frameworks derived carbon with abundant Zn clusters, after infusion the lithium, the high active nano Zn clusters could react with lithium for form the Li-Zn alloy as shown in Figure 5d[98]. Therefore, a 3D conductive carbon supported Li-Zn alloy structure has realized, which enabled the homogenization of the distributions of electric field and $\mathrm{Li}$ ion flux. The Li-Zn alloy layer rendered the matrix to have good affinity with lithium, and acted as a buffer layer for the following Li plating, effectively eliminating nucleation barriers. And Zhang and his co-workers proposed another kind of 3D carbon supported Li-Zn alloy structure by infiltrating lithium into carbon cloth decorated with zinc oxide arrays as shown in Figure 5e[103]. The XRD spectrum as shown in Figure 4f confirmed the formation of LiZn 
alloy in Li-CC@ZnO. Such a LiZn alloy formation in the Li plating process further induced dendrite-free Li deposition. As a result, a low overpotential of $\sim 243 \mathrm{mV}$ over 350 cycles at a high current density of 10 $\mathrm{mA}^{*} \mathrm{~cm}^{-2}$ was achieved (shown in Figure 5f), compared to the seriously fluctuated voltage and fast short circuit in the cell using bare Li metal.

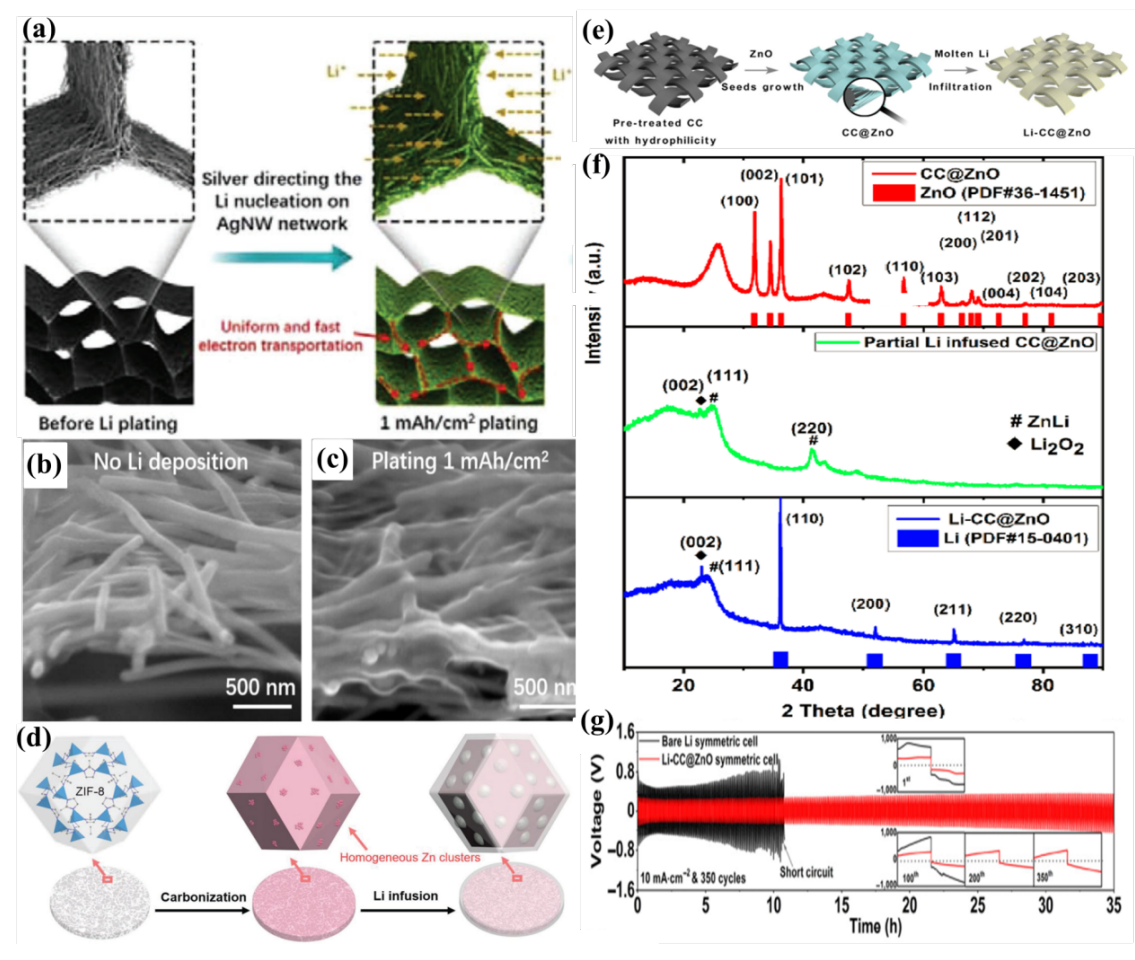

Figure 5 (a) Schematic illustration of the Li plating in the 3D-AGBN host at a current density of 1 $\mathrm{mA} \cdot \mathrm{h} \cdot \mathrm{cm}^{-2}$, Magnified SEM images showing the AgNWs nanonetwork (b) before and (c) after plating 1 $\mathrm{mA}^{*} \mathrm{~h}^{*} \mathrm{~cm}^{-2}$ of Li in the 3D-AGBN host. (Reproduced from ref.[99], with permission from Copyright (c) 2018 WILEY-VCH.) (d) Schematic representation exhibits the fabrication process of Li-cMOFs. (Reproduced from ref.[98], with permission from Copyright (c) 2018 WILEY-VCH.) (e) Schematic fabrication process of Li-CC@ZnO electrode, (f) XRD patterns of CC@ZnO electrode before and after partial Li infiltration, and Li-CC@ZnO electrode. After Li infiltration, the original diffraction peaks of $\mathrm{ZnO}$ disappear, instead, (111) and (220) diffractions of $\mathrm{Li}-\mathrm{Zn}$ alloy and (002) of $\mathrm{Li}_{2} \mathrm{O}_{2}$ appear. They are derived from the reaction of molten Li with Zn. (g) Electrochemical performance comparisons of the Li-CC@ZnO (red) and bare Li foil (black) symmetric cells. Cyclic stabilities with a Li capacity of $10 \mathrm{~mA}^{*} \mathrm{~cm}^{-2}$. (Reproduced from ref.[103], with permission from Copyright (c) 2018 Tsinghua University Press and Springer-Verlag GmbH Germany, part of Springer Nature.)

Except using the 3D alloy matrix to host metallic lithium, recently researchers pay attention on various 3D $\mathrm{Cu}$-alloys current collector. After the 3D Cu current collector modified by active metals, such as $\mathrm{Al}[104]$, $\mathrm{Sn}[101], \mathrm{Zn}[105], \mathrm{Au}[25]$, Ga-based liquid metal alloys[106], etc., it can form Li alloys after in-situ electrochemically deposition $\mathrm{Li}$ and then served as seeds to induce the formation of non-dendritic $\mathrm{Li}$ via lowering $\mathrm{Li}$ nucleation overpotential and interfacial energy. For example, Guo's group reported a 3D Cu fibers grown on the $\mathrm{Cu}$ foil coating with a thin $\mathrm{Al}$ layer[104], forming a 3D $\mathrm{Cu} @ \mathrm{Al}$ hybrid structure; after an initial discharge process above $0 \mathrm{~V}$ vs. $\mathrm{Li}^{+} / \mathrm{Li}$, the thin $\mathrm{Al}$ layer reacted with $\mathrm{Li}$ to generate a binary $\mathrm{Li}-\mathrm{Al}$ alloy phase, which functioned as the lithiophilic sites. The Li nucleation and growth promoted by Li-Al alloy layer realize a dendrite-free $\mathrm{Li}$ anode as shown in Figure $6 \mathrm{a}$ and $6 \mathrm{~b}$. In addition, by controlling the discharge process, the active $\mathrm{Li}$ stored in the form of $\mathrm{Li}-\mathrm{Al}$ alloy could act as a $\mathrm{Li}$ resource to compensate any irreversible Li loss 
during cycling. D. Abruna et al., reported a $\mathrm{Zn}$ coated Cu foil current collector[105]. During the Li plating process, the $\mathrm{Li}-\mathrm{Zn}$ alloy buffer layer on the $\mathrm{Cu}$ foil surface would regulate the nucleation and growth of $\mathrm{Li}$ metal as shown in Figure 6c. As expectedly, the Coulombic efficiencies of plating/stripping was enhanced and nucleation overpotential was greatly reduced. And they also investigated the electrochemical performances of high-energy-density Li-S full cells by using the $\mathrm{Zn}$ coated $\mathrm{Cu}$ foils as Li metal current collectors. As shown in Figure 6d, the cycling stability of these two kinds of batteries was significantly enhanced.
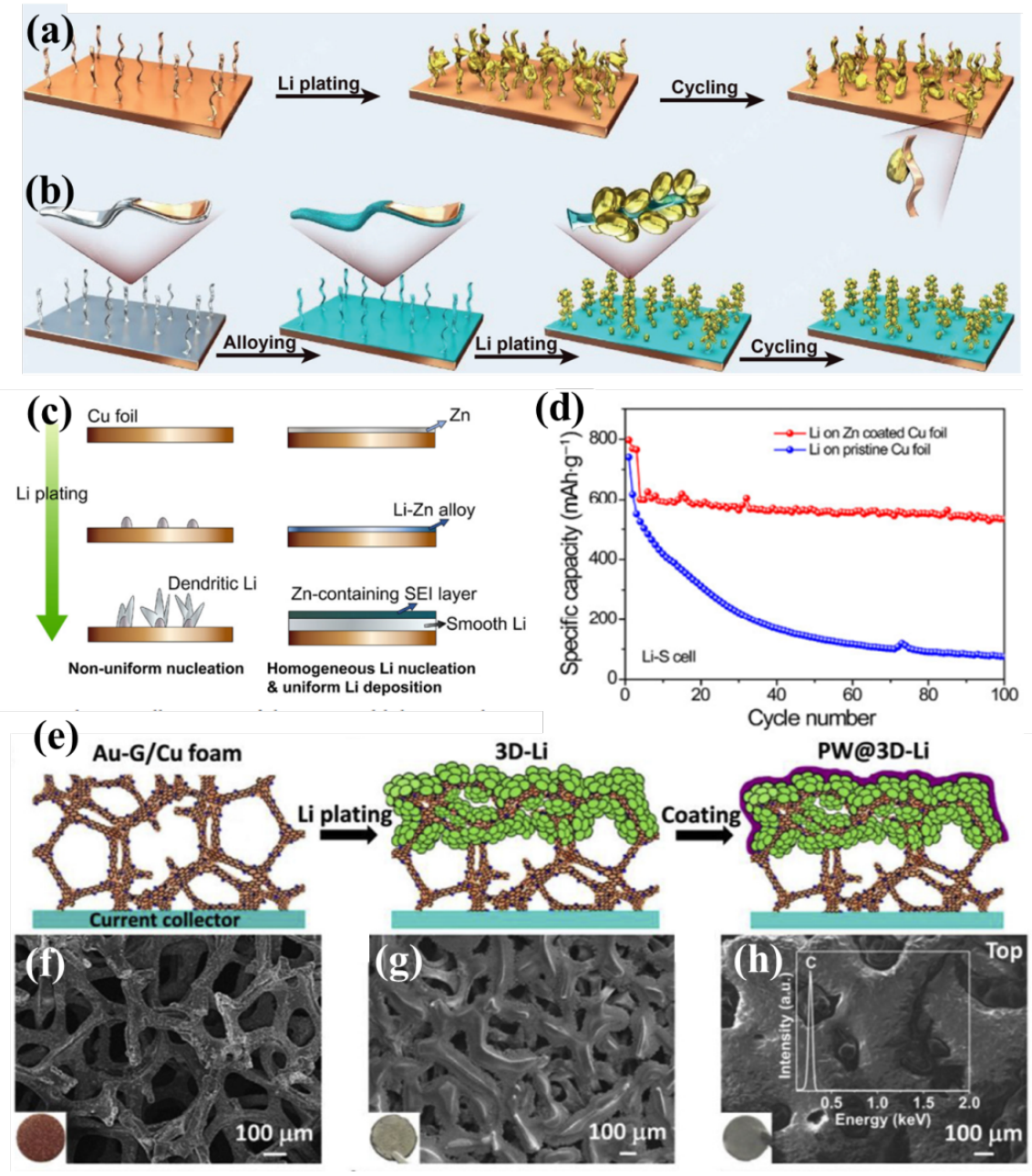

Figure 6 Schematic of the Li plating process on the (a) 3D Cu foil and (b) 3D Cu@Al foil. (Reproduced from ref.[104], with permission from Copyright (C) 2019 Wiley-VCH.) (c) Schematic illustration of the proposed lithium nucleation and deposition processes on a bare $\mathrm{Cu}$ foil (left) and a $\mathrm{Zn}$ modified $\mathrm{Cu}$ foil (right), (d) Cycling performance of Li-S full cells tested at $0.2 \mathrm{C}$ for the first 3 cycles and at $0.5 \mathrm{C}$ for the subsequent cycles with $\mathrm{Li}$ pre-deposited on a pristine $\mathrm{Cu}$ foil or a $\mathrm{Zn}$ coated $\mathrm{Cu}$ foil as the anode. (Reproduced from ref.[105], with permission from Copyright (C) 2019 Tsinghua University Press and Springer-Verlag GmbH Germany, part of Springer Nature.) (e) Schematic illustration of the preparation process of PW@3D-Li, SEM images of (f) Au-G/Cu foam, (g) 3D Li and (h) PW@3D-Li, Lower-left inserts in (f), (g) and (h) represent optical photographs of $\mathrm{Cu}$ foam, 3D-Li and PW@3D-Li, respectively. (Reproduced from ref.[25], with permission from Copyright (C) 2019 Elsevier B.V.)

Trapping Li into three-dimensional (3D) conductive host to construct 3D-Li is an effective strategy to 
suppress the growth of Li dendrites. However, the increased contact area between 3D-Li and electrolyte unavoidably induces more side reactions to further deteriorate the electrochemical performance of lithium metal batteries. In order to keep the advantages of 3D lithium-alloys matrix as well as reduce the side effect, recently, Qu's group construct a paraffin wax (PW) coating Au-graphene/Cu foam current collector[25]. Such a unique structure was able to effectively avoid the growth of Li dendrites and formation of "dead Li" during the Li plating process, which could be attributed to these merits: i) Au could react with Li to form $\mathrm{Li}_{x} \mathrm{Au}$ alloys that lowered $\mathrm{Li}$ nucleation overpotential and interfacial energy to effectively inhibit the formation of dendritic Li; ii) 3D lithiophilic graphene decreased the local current density and enabled the homogeneous growth of $3 \mathrm{D} \mathrm{Li}$; iii) $\mathrm{Cu}$ skeleton not only afforded interconnected pores to accommodate the volume variation of 3D-Li, but also served as a robust support to avoid the collapse of overall electrode especially during fast plating/stripping processes; iv) the PW protection layer confined Li during the plating and stripping to mitigate the corrosion of electrolyte and depress the formation of Li dendrites and "dead Li".

\subsection{Artificial protective layers for lithium alloys anodes}

Even using the 3D matrix to host the Li-containing alloys, unfortunately, these materials still suffer from poor SEI stability, resulting in unsatisfied electrochemical performances[48]. Therefore, constructing an artificial protective layer for lithium alloys anodes has been proposed. For example, Cui's groups reported two methods to construct artificial-SEI layer of $\mathrm{LiF}$ to protect $\mathrm{Li}_{x} \mathrm{Si}$ alloy nanoparticles via reducing 1-fluorodecane and fluoropolymer CYTOP, respectively[107, 108]. Ci et al., reported a $\mathrm{Li}-\mathrm{O}_{2}$ coin cell with the $\mathrm{LiAl}_{x}$ anode experienced a high-current pretreatment[109], as a result, the SEI film (including $\mathrm{Al}_{2} \mathrm{O}_{3}, \mathrm{LiF}, \mathrm{ROCO}_{2} \mathrm{Li}$, $\mathrm{LiOH}$, and $\mathrm{Li}_{2} \mathrm{CO}_{3}$ ) formed after the pretreatment process facilitated the uniform $\mathrm{Li}^{+}$shuttling during the following $\mathrm{Li}$ plating/stripping process and stabilizes the $\mathrm{LiAl}_{x}$ anode interface even after hundreds of cycles. The $\operatorname{LiAl}_{x}$ anode in lithium oxygen batteries could increase cycling to 667 cycles under a fixed capacity of $1000 \mathrm{~mA} \cdot \mathrm{h} \cdot \mathrm{g}^{-1}$ compared to 17 cycles of $\mathrm{LiAl}_{x}$ anode without pre-treatment. Recently, Zhang's group used a Li-Na alloy and 1,3-dioxolane (DOL) as anode and additive, respectively, to control dendrite growth and buffer the volume expansion of the alloy anode[85]. The 1,3-dioxolane additive could in situ react with Li-Na alloy to form a robust and flexible passivation film that suppress dendrite growth, buffer alloy anode volume expansion, prevent cracking. As shown in Figure 7a-7d, only the Li-Na alloy electrode with DOL additive existence can effectively suppress dendrite growth and wouldn't crack after cycling. 


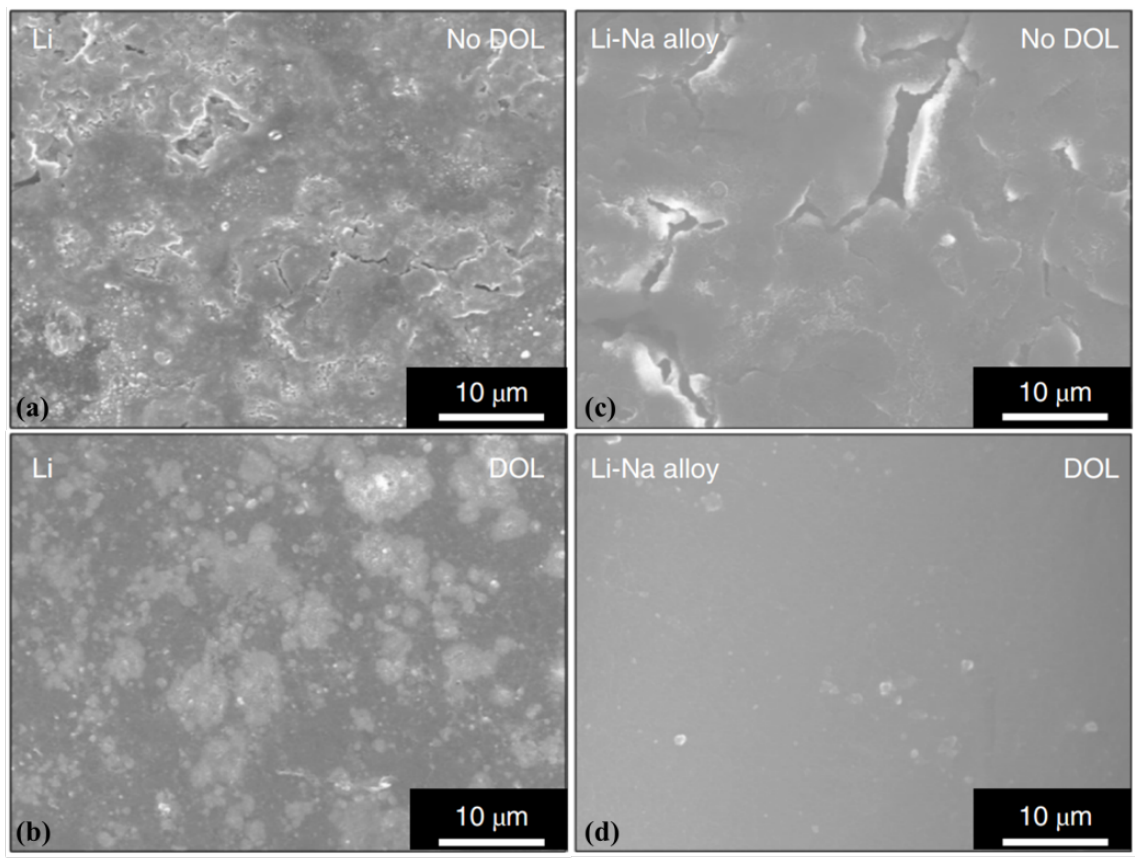

Figure 7 SEM images for (a, c) Li electrode and (b, d) Li-Na alloy electrode with a Na/Li molar ratio of 6 after five stripping/plating cycles in $0.5 \mathrm{M} \mathrm{NaCF}_{3} \mathrm{SO}_{3} /$ TEGDME or $\mathrm{NaCF}_{3} \mathrm{SO}_{3} / \mathrm{DOL} / \mathrm{TEGDME}$ electrolyte. (Reproduced from ref.[85], with permission from Copyright (C) 2018 The Author(s), under exclusive license to Springer Nature Limited.)

While a more common strategy to form an artificial SEI layer is using Li salts to in-situ react with lithium alloys. It is easy to realize a thin lithium alloy layers on the surface of Li metal by in situ reduction of metal salts as shown in Eqns 1[110]:

$$
\begin{array}{ll}
\hline x \mathrm{Li}+\mathrm{MA} x-\mathrm{M}+\mathrm{LiA}(\mathrm{M}: \text { metal, A: halogen) } & \text { Eqns1 } \\
\hline
\end{array}
$$

More importantly, the metal layer could immediately undergo reaction with the underlying lithium to form the Li alloy as shown in Eqns 2[110]:

$$
\overline{y \mathrm{Li}+z \mathrm{M}-\operatorname{Li} y \mathrm{M} z \quad \text { Eqns2 }}
$$

For instance, in 2017, Nazar's group reported Li-rich composite alloy films synthesized in situ on lithium by the above two reactions[110]. Due to the lithium alloy and lithium salt composites together form an artificial SEI layer to protect the lithium anode, it can sustain electrodeposition over 700 cycles $(1,400 \mathrm{~h})$ of repeated plating/stripping at a practical current density of $2 \mathrm{~mA} \cdot \mathrm{cm}^{-2}$ and a 1,500 cycle-life was realized for a cell paired with a $\mathrm{Li}_{4} \mathrm{Ti}_{5} \mathrm{O}_{12}$ positive electrode. Following then, various lithium alloy-lithium salts artificial SEI layers have been proposed, and Table 2 made a conclusion. It can be observed that the metal halides are the most popular candidates to react with lithium and form an inorganic composite artificial SEI layers.

Table 2 Various lithium alloy-lithium salts artificial SEI layers.

\begin{tabular}{lllll}
\hline Metal salts & Lithium Salts & Lithium alloys & Artificial SEI layers & references \\
$\mathrm{BiF}_{3}$ & $\mathrm{LiF}$ & $\mathrm{Li}-\mathrm{Bi}$ & $\mathrm{LiF} / \mathrm{Li}-\mathrm{Bi}$ & {$[111]$}
\end{tabular}




\begin{tabular}{lllll}
$\mathrm{InCl}_{3}$ & $\mathrm{LiCl}$ & $\mathrm{Li}-\mathrm{In}$ & $\mathrm{LiCl} / \mathrm{Li}-\mathrm{In}$ & {$[110]$} \\
$\mathrm{ZnCl}_{2}$ & $\mathrm{LiCl}$ & $\mathrm{Li}-\mathrm{Zn}$ & $\mathrm{LiCl} / \mathrm{Li}-\mathrm{Zn}$ & {$[110][112]$} \\
$\mathrm{BiCl}_{3}$ & $\mathrm{LiCl}$ & $\mathrm{Li}-\mathrm{Bi}$ & $\mathrm{LiCl} / \mathrm{Li}-\mathrm{Bi}$ & {$[110]$} \\
$\mathrm{AsCl}_{3}$ & $\mathrm{LiCl}$ & $\mathrm{Li}-\mathrm{As}$ & $\mathrm{LiCl} / \mathrm{Li}-\mathrm{As}$ & {$[110]$} \\
$\mathrm{CaCl}_{2}$ & $\mathrm{LiCl}$ & $\mathrm{Li}-\mathrm{Ca}$ & $\mathrm{LiCl} / \mathrm{Li}-\mathrm{Ca}$ & {$[112]$} \\
$\mathrm{MgCl}_{2}$ & $\mathrm{LiCl}$ & $\mathrm{Li}-\mathrm{Mg}$ & $\mathrm{LiCl} / \mathrm{Li}-\mathrm{Mg}$ & {$[112]$} \\
$\mathrm{AlCl}_{3}$ & $\mathrm{LiCl}$ & $\mathrm{Li}-\mathrm{Al}$ & $\mathrm{LiCl} / \mathrm{Li}-\mathrm{Al}$ & {$[112][113][114]$} \\
$\mathrm{SiCl}_{4}$ & $\mathrm{LiCl}$ & $\mathrm{Li}-\mathrm{Si}$ & $\mathrm{LiCl} / \mathrm{Li}-\mathrm{Si}$ & {$[115]$} \\
$\mathrm{GeCl}_{4}$ & $\mathrm{LiCl}$ & $\mathrm{Li}-\mathrm{Ge}$ & $\mathrm{LiCl} / \mathrm{Li}-\mathrm{Ge}$ & {$[116]$} \\
$\mathrm{HAuCl}_{4}$ & $\mathrm{LiCl}$ & $\mathrm{Li}-\mathrm{Au}$ & $\mathrm{LiCl} / \mathrm{Li}-\mathrm{Au}$ & {$[117]$} \\
$\mathrm{AlI}_{3}$ & $\mathrm{LiI}$ & $\mathrm{Li}-\mathrm{Al}$ & $\mathrm{LiI} / \mathrm{Li}-\mathrm{Al}$ & {$[118]$} \\
$\mathrm{AgNO}_{3}$ & $\mathrm{LiNO}$ & $\mathrm{Li}-\mathrm{Ag}$ & $\mathrm{LiNO} / \mathrm{Li}-\mathrm{Ag}$ & {$[117]$} \\
\hline
\end{tabular}

However, these inorganic films are often thin, brittle, and vulnerable to cracking due to the volume effect of the $\mathrm{Li}$ anode during extended cycling[32]. Thus, a more flexible artificial SEI layers, such as polymerlithium alloy hybrid artificial SEI layers[119, 120], has be developed. For example, Xie et al reported a poly(tetramethylene ether glycol) (PTMEG)-Li/Sn alloy hybrid layer on the Li metal surface[119]. The possible mechanism for forming the artificial SEI layer is shown in Figure 8a. Such a hybrid artificial layer not only provided a fast lithium-ion transport path on account of the Li/Sn alloy with ample Li vacancies, but also has a strong affinity for Li. Since PTMEG is similar to poly(ethylene oxide) (PEO) with a large number of C-O bonds. As a result, after only 20 cycles, many dendrites and dead Li were observed for the pristine $\mathrm{Li}$, whereas the treated $\mathrm{Li}$ presents a smooth and compact deposition of $\mathrm{Li}^{+}$as shown in Figure $8 \mathrm{~b}$ and $8 \mathrm{c}$.

\section{(a) Reaction 1}

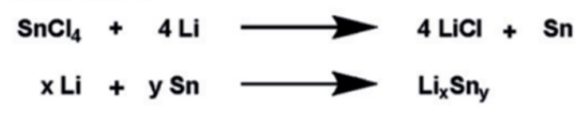

Reaction 2

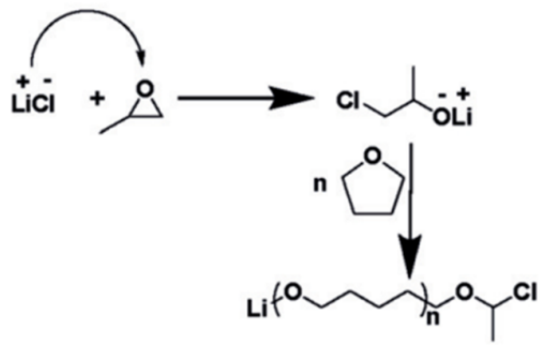

Reaction 3

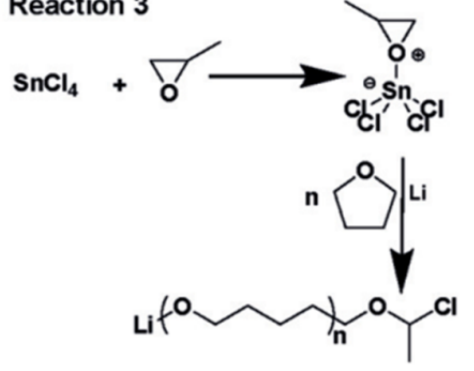

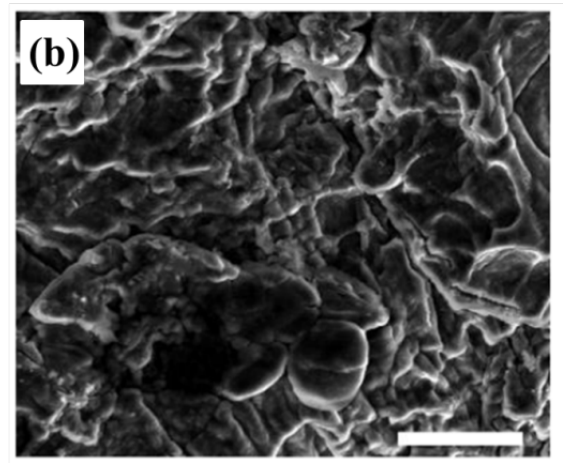

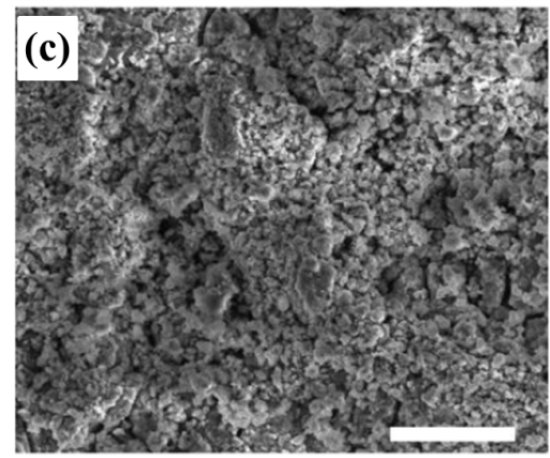


Figure 8 (a) Possible reaction mechanism for the formation of the PTMEG-Li/Sn alloy hybrid layer. SEM images of $\mathrm{Li}-\mathrm{Li}$ symmetric cells with (b) the pristine $\mathrm{Li}$ and (c) $\mathrm{SnCl}_{4}+\mathrm{THF}$ treated $\mathrm{Li}$ after 20 cycles at $1 \mathrm{~mA} \cdot \mathrm{cm}^{-2}, 1 \mathrm{~mA}^{*} \mathrm{~h}^{*} \mathrm{~cm}^{-2}$. All scale bars are $20 \mu \mathrm{m}$. (Reproduced from ref.[119], with permission from Copyright (C) 2019 Wiley-VCH.)

Moreover, researchers have also developed various kinds of lithium-containing alloys artificial protective layers. The protective lithium alloy layers are generally thin films formed on the Li metal surface via chemical/electrochemical pre-treatment[85, 109-120], mechanical press[121, 122], magnetron sputtering[60], etc., which are acceptable ionic conductivity for Li migration as well as suppress the dendrite growth via homogenous deposition of lithium[32]. For example, Li group reported a magnetron sputtering method to deposit a thin Al film on lithium surface[60]. After depositing, the Li-Al alloy layer would be formed on the lithium metal surface and guide dense Li deposition. Mai's group reported an artificial Li-Al interphase layer on Li-B alloy anode[121, 122]. The Li-Al layer form in situ on the Li-B electrode via pressing $\mathrm{Al}$ foil with Li-B foil discs under a pressure of $120 \mathrm{Mpa}$, then kept at this pressure for several minutes or lithiated after $10 \mathrm{~min}$. The artificial Li-Al layer allowed electron and ion transport to Li-B electrode. The Li-Al layer coating on Li-B electrode can improve cyclic life over $1200 \mathrm{~h}$ at a current density of $0.2 \mathrm{~mA} \cdot \mathrm{cm}^{-2}$, whereas bare Li-B electrode has stable cycles not exceeding $800 \mathrm{~h}$. In addition, when it assembled with $\mathrm{LiMn}_{0.8} \mathrm{Fe}_{0.2} \mathrm{PO}_{4}$ cathode and $\mathrm{Li}_{1.5} \mathrm{Al}_{0.5} \mathrm{Ge}_{1.5}\left(\mathrm{PO}_{4}\right)_{3}$ electrolyte, the resulted solid state batteries could deliver an initial discharge capacity of $153 \mathrm{~mA}^{*} \mathrm{~h}^{*} \mathrm{~g}^{-1}$ with good cyclic stability and rate performance at $50 \mathrm{degC}$.

\section{4 | LITHIUM ALLOYS MODIFIED ELECTROLYTES}

In the past decades, all-solid-state Li batteries received increasing attentions due to nonflammability, dendrite blocking, and stability over large potential windows[123]. But how to realize high safety, high power density, and high energy density for all-solid-state Li batteries is still a challenge. Recently, Hu's group creatively combined the lithium alloy anode with garnet electrolyte to solve the problems of all-solid-state Li batteries[123-126]. For example, in 2017, they first proposed a new methodology for reducing the garnet/Limetal interfacial resistance by forming Li-Ge alloy. First a thin Ge layer $(20 \mathrm{~nm})$ was evaporated onto the garnet pellet by an electron beam evaporation system, then put a small piece of Li metal disc on the Ge-modified garnet, after heating, the Li-Ge alloy anode would be formed. Because the effective contact area between Ge-modified-garnet and Li-metal anode increased more than eight times compared to bare garnet due to the alloying reaction between $\mathrm{Li}$ and $\mathrm{Ge}$ as shown in Figure 9a, the Li/Ge-modified garnet delivered a small interfacial resistance of $115 \Omega \cdot \mathrm{cm}^{2}$, far smaller than the Li/bare garnet ([?]900 $\left.\Omega \cdot \mathrm{cm}^{2}\right)$. When it assembled with $\mathrm{LiFePO}_{4}$ to form an all-solid-state Li battery as shown in Figure 9b, the cycling performance of this all-solid-state Li battery has been improved significantly, even comparable with the full batteries using the liquid electrolyte as shown in Figure 9c. Even the coulombic efficiency was better than the full cells using liquid electrolyte in Figure 9d. 
(a)
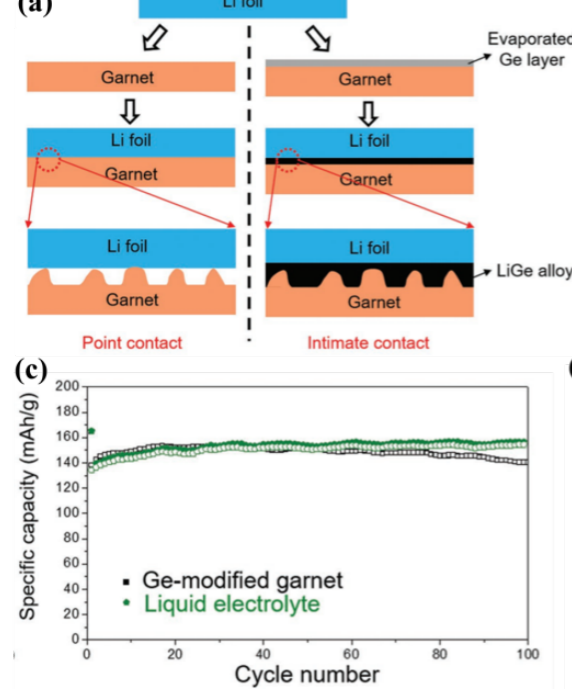

(b)

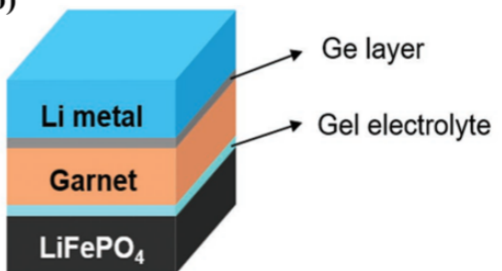

Li/Ge-modified garnet/LFP full cell

(d)

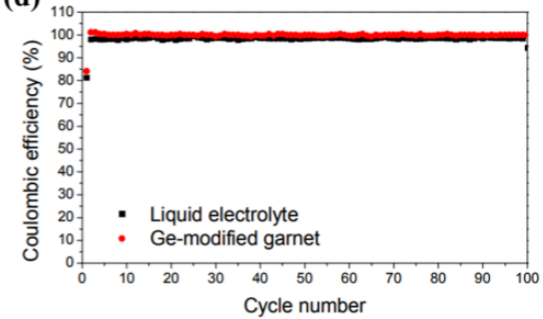

Figure 9 (a) Schematic representation for improving the contact between garnet and Li metal by engineering the surface of the garnet with a thin Ge layer. The Ge layer, evaporated onto garnet, can alloy with Li metal, which leads to more continuous interfaces between the garnet and Li metal and results in a small interfacial resistance. (b) Schematic of the full cell structure, where a gel membrane was used between garnet and LFP cathode. (c) Cycling performance of the Li/Ge-modified-garnet/LFP cell and Li/liquid-electrolyte/LFP cell at 1 C. (d) Coulombic efficiencies of Li/Ge-modified-garnet/LFP cell and Li/liquid-electrolyte/LFP cell at 1 C. (Reproduced from ref.[126], with permission from Copyright (C) 2017 Wiley-VCH.)

Since then, the Li-Zn, Li-Sn and Li-Mg alloy modified garnet solid electrolytes have subsequently developed[123-125]. Such a facile surface treatment on garnet electrolyte with forming lithium alloys method offered a simple strategy to solve the interface problem in solid-state lithium metal batteries.

\section{5 | Lithium Alloys modified separators}

A multifunctional separator through coating a thin electronic conductive film on one side of the conventional polymer separator facing the Li anode could contribute to Li dendrite suppression and cycling stability improvement[127]. Recently, $\mathrm{Li}$ and his co-workers developed a multifunctional lithium alloys coating separator by reducing the $\mathrm{PbZr}_{0.52} \mathrm{Ti}_{0.48} \mathrm{O}_{3}(\mathrm{PZT})$ coating layer on polypropylene (PP) separator[128]. The produced $\mathrm{Li}-\mathrm{Pb}$ alloy armor between the separator and $\mathrm{Li}$ anode, not only uniformed the electric field across the interface but also mitigated the Li metal nucleation, and therefore suppressed the dendrite growth during plating. As a result, the $\mathrm{Li} / \mathrm{Li}$ symmetric cells and $\mathrm{LiFePO}_{4} / \mathrm{Li}$ cells with this such PZT-pretreated PP separators exhibit significantly improved Coulombic efficiency and cycling life as shown in Figure 10a and 10b. 

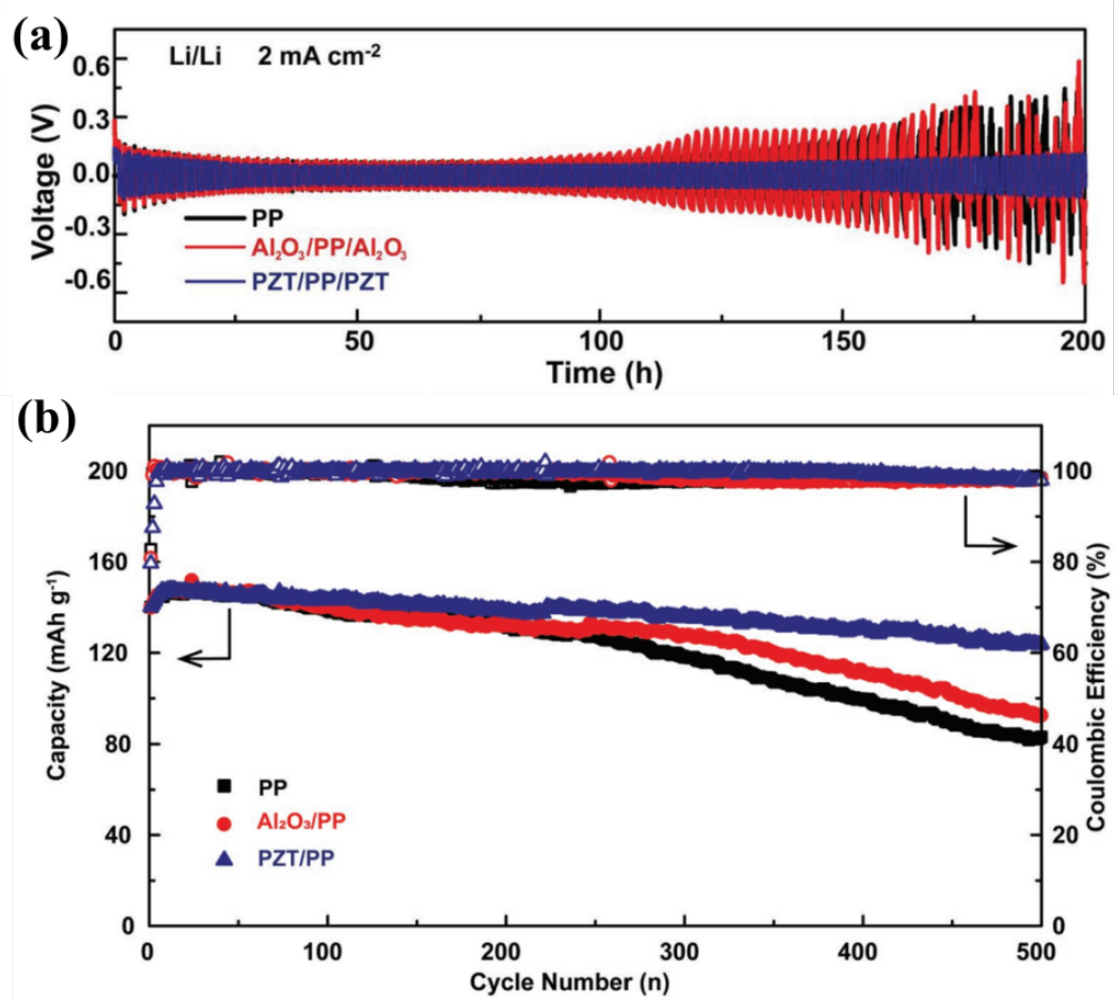

Figure 10 (a) Cycling behaviors of $\mathrm{Li} / \mathrm{Li}$ symmetric cells separated by $\mathrm{PP}, \mathrm{Al}_{2} \mathrm{O}_{3} / \mathrm{PP} / \mathrm{Al}_{2} \mathrm{O}_{3}$, and $\mathrm{PZT} / \mathrm{PP} / \mathrm{PZT}$ at $2 \mathrm{~mA} \cdot \mathrm{cm}^{-2}$ with an area capacity of $2 \mathrm{~mA}^{*} \mathrm{~h}^{*} \mathrm{~cm}^{-2}$. (b) Cycling performance of LFP/Li cells with $\mathrm{PP}, \mathrm{Al}_{2} \mathrm{O}_{3} / \mathrm{PP}$, or $\mathrm{PZT} / \mathrm{PP}$ separator and $1 \mathrm{M} \mathrm{LiPF}_{6}$ in EC/DMC at $25 \operatorname{deg}$ at $0.5 \mathrm{C}[128]$. (Reproduced from ref.[128], with permission from Copyright (c) 2019Wiley-VCH.)

\section{Perspective on Li-containing alloys for high-safety and high-energy density batteries}

The introduction of Li-containing alloys seems to be a fundamental tool to resolve the safety hazards caused by lithium dendrites. But there are still many unanswered questions, for instance, the protective mechanisms for different alloys are not clearly understood[86]; the Li-containing alloy materials can effectively improve the state of first-layer Li deposition, however, the substrate will revert to pure $\mathrm{Li}$ as deposition continues[54]; the Li-containing alloy anodes still face the great volume change and serious side reaction during the striping/plating process, etc. Therefore, these scientific problems are still urgently awaiting our solutions.

Simply using lithium metal alloy anode/lithium alloy artificial SEI film or using lithium alloy to modify the current collector, separator and electrolytes cannot fully solve the challenges faced by lithium anode. Only by combining multiple strategies can the problems caused by lithium anode be better or completely solved. Here we proposed several suggestions (as shown in Figure 11) for the future research of lithium-containing alloys employed in Li metal batteries:

i) As the binary Li-containing alloy either has the high reaction activity (i.e Li-Na), or the great volume change (i.e. $\mathrm{Li}-\mathrm{Si}, \mathrm{Li}-\mathrm{Sn}$ ), or the low energy density (i.e. Li-Bi, Li-Zn), or the high cost (i.e. $\mathrm{Li}-\mathrm{Ag}, \mathrm{Li}-\mathrm{Cu}$ ) each kind of shortcoming, it can take more consideration into ternary/multicomponent lithium alloys, which 
can make up for each other through multiple components. But the presence of additional metal that are not directly involved in electrochemical reaction results in additional weight and volume and thus cause the specific energy density reducing compared to using the pure lithium or binary lithium alloy anodes[129]. Another disadvantage is that there still exist a substantial change in specific volume upon charging and discharging alloy electrode reactants, can lead to loss of electrical contact, and thus capacity loss[129]. In addition, the complexity and cost of preparing ternary/ multicomponent lithium alloys also need to be considered

ii) Considering the substantial volume change exactly exists in lithium-containing alloys anodes, constructing nanostructures to host lithium alloy or preparing lithium alloy-based composites is also a good choice[130, 131]. By encapsulating the lithium alloy into special nanostructures, i.e. 3D graphene[132], CNT[131], etc., or using polymers coating[25], the volume change of lithium alloy has been effectively eliminated, because of these nanostructured host or extra components, Li-containing alloy anodes will be more stable in the organic electrolyte and the lithium dendrite would also be effectively inhibited.

iii) Constructing artificial protection/SEI layer on the lithium alloy anode, i.e., recently Won II Cho et al., reported a $\mathrm{Li}-\mathrm{Al}$ anode protected by a Langmuir-Blodgett artificial SEI composed of $\mathrm{MoS}_{2}[133]$. Such a $\mathrm{MoS}_{2}$ artificial SEI layer exhibited a combination of a high Li binding energy, molecular smoothness, and low barrier to Li adatom diffusion, which favors efficient binding of $\mathrm{Li}$ and transport away from the electrode/electrolyte interface as well as favors stable and reversible Li migration of the $\mathrm{MoS}_{2}$ coating Li- $\mathrm{Al}$ anode. As a result, the $\mathrm{MoS}_{2}$ coating Li-Al alloy anode exhibited high reversibility stable Li migration during recharge of the cells compared to the Li-Al alloy anode without the $\mathrm{MoS}_{2}$ coating.

iv) Developing the suitable electrolytes and separators for lithium-containing alloys anodes. Modification of electrolyte or separators with lithium alloy will limit its application in lithium metal batteries, as electrolyte components have significantly influences on the electrochemical performances of electrodes, no matter anode or cathode. For example, the absence of volatile or flammable compounds is expected to make solid electrolytes safer than their liquid counterparts at elevated temperatures[11]. Additives, can decompose, polymerize or adsorb on the Li surface, modifying the physico-chemical properties of the SEI and therefore regulating the current distribution during Li deposition[19, 23, 134]. Solvents, i.e, the ionic liquid, shows an exciting role in improving the low temperature performances of batteries[135]. Lithium salts could not only benefit to stabilize the spontaneous solid electrolyte interphase (SEI) films, but also control the nucleation and growth of metallic lithium, thus enhancing the stabilities of lithium anodes during the stripping and plating processes[21, 136].

While separators serving as a physical barrier between electrodes, traditional polyolefin-based separators easily suffer a "shut-down" problem when penetrate through lithium dendrites or exposed to overheating and/or overcharge[11]. A suitable separator for lithium-containing alloys anodes should have good thermal stability and function to suppress the lithium dendrites. Additionally, a suitable separator may also have the function to inhibit the polysulfides shuttling for Li-S batteries and for Li-air batteries. Therefore, a better strategy is combing the lithium alloys anodes with various functional electrolytes and separators rather than use it to modify the electrolyte or separators. 


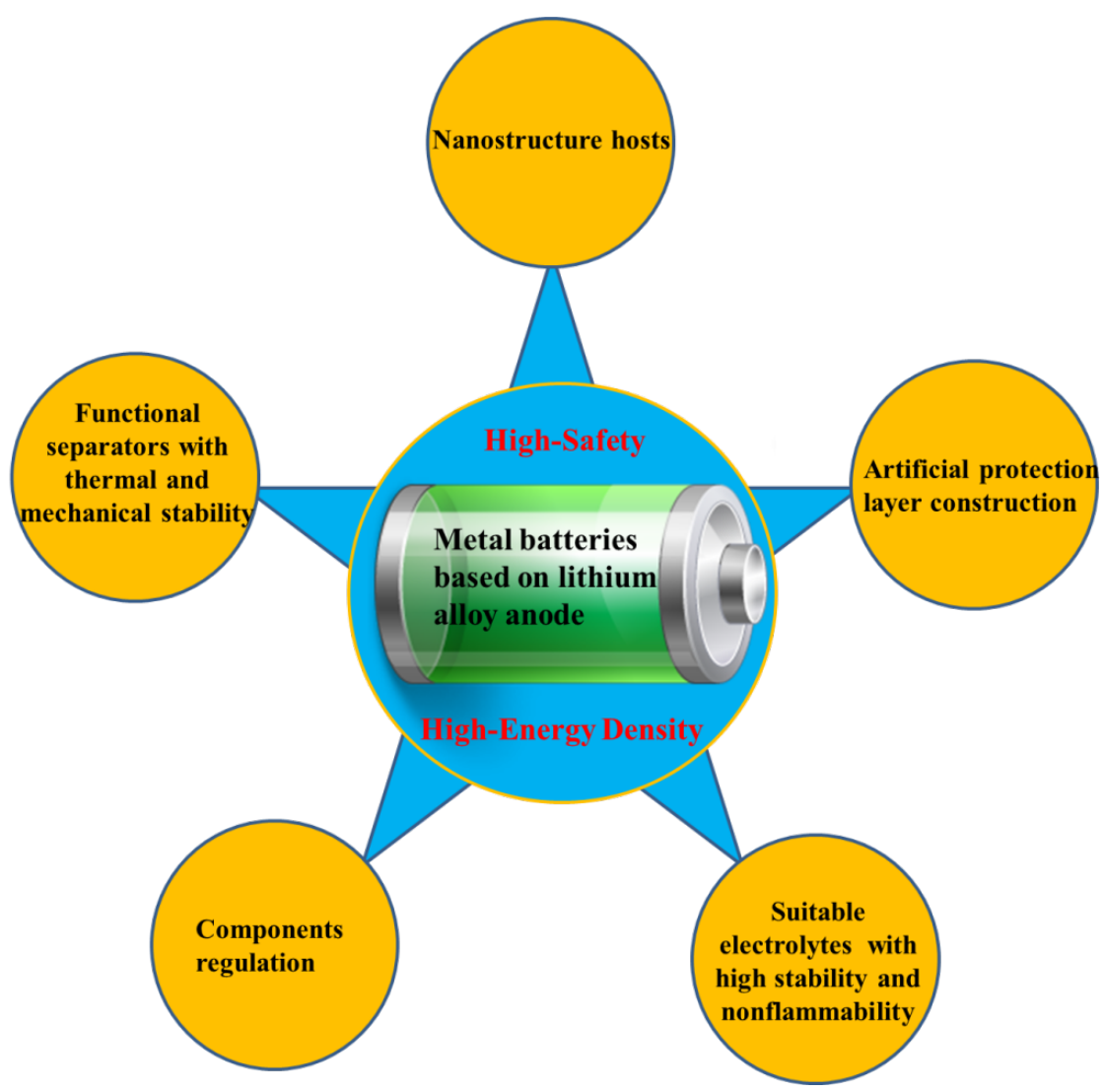

Figure 11 The potential solving strategies towards the future high-safety and high-energy-density metal batteries based on the lithium alloys anodes.

Finally, we want to emphasize that more efforts should be devoted to develop the Li-containing alloys anodes suitable for Li-S batteries and Li-air batteries, as firstly, the energy density of LIBs is limited, which could not meet the future electric vehicles and grid energy storage markets; secondly as the higher reduction of polysulfide anions in Li-S batteries and higher oxidation of superoxide radical anions in Li-air batteries, some of Li-containing alloy anodes may be used stably in LIBs but not stable in Li-S and Li-air batteries. Therefore, Li metal protection in Li-S and Li-air batteries is more complicated compared with lower energy density LIBs. In a word, we believe that through our unremitting efforts, the Li-containing alloys anodes will show great potentials in the high-safety and high-energy-density battery systems.

\section{ACKNOWLEDGEMENTS}

This work is financially supported by the National Natural Science Foundation of China (No. 51871113 and 51902036), Natural Science Foundation of Chongqing Science \& Technology Commission (No. cstc2019jcyjmsxm1407), Natural Science Foundation of Chongqing Technology and Business University (No. 1952009), the Key Research and Development Program of Xuzhou (KC17004), the Science and Technology Research Program of Chongqing Education Commission (No. KJQN201900826 and KJQN201800808), the Venture \& Innovation Support Program for Chongqing Overseas Returnees (Grant No. CX2018129) and the Innovation Group of New Technologies for Industrial Pollution Control of Chongqing Education Commission (Grant No. CXQT19023).

\section{CONFLICT OF INTEREST}

The authors declare no potential conflict of interest. 


\section{AUTHORSHIP AND CONTRIBUTORSHIP}

Dr. X. Gu and Dr. C. Lai conceive the idea; all authors contribute to writing this review.

\section{REFERENCES}

[1] M. S. Whittingham, "Electrical energy storage and intercalation chemistry," Science, vol. 192, no. 4244, pp. 1126-1127, 1976. DOI: https://doi.org/10.1126/science.192.4244.1126.

[2] D. Lin, Y. Liu and Y. Cui, "Reviving the lithium metal anode for high-energy batteries," Nature Nanotechnology, vol. 12, no. 3, pp. 194-206, 2017. DOI: https://doi.org/ 10.1038/nnano.2017.16.

[3] K. Brandt, "Historical development of secondary lithium batteries," Solid State Ionics, vol. 69, no. 3-4, pp. 173-183, 1994. DOI: https://doi.org/10.1016/0167-2738(94)90408-1.

[4] Y. Guo, H. Li and T. Zhai, "Reviving lithium-metal anodes for next-generation high-energy batteries," Advanced Materials, vol. 29, no. 29, 1700007, 2017. DOI: https://doi.org/10.1002/adma.201700007.

[5] X.-B. Cheng, C.-Z. Zhao, Y.-X. Yao, H. Liu and Q. Zhang, "Recent advances in energy chemistry between solid-state electrolyte and safe lithium-metal anodes," Chem, vol. 5, no. 1, pp. 74-96, 2019. DOI: https://doi.org/10.1016/j.chempr.2018.12.002.

[6] Y. Ji, S. Weng, X. Li, Q. Zhang, L. Gu, "Atomic-scale structural evolution of electrode materials in Li-ion batteries: a review, " Rare Metals, vol.29, no. 3, pp. 205-217. DOI: https://doi.org/10.1007/s12598-02001369-6

[7] X. Gu, T. Tang, X. Liu and Y. Hou, "Rechargeable metal batteries based on selenium cathodes: Progress, challenges and perspectives," Journal of Materials Chemistry A, vol. 7, no. 19, pp. 11566-11583, 2019. DOI: https://doi.org/10.1039/C8TA12537F.

[8] H. Yuan, H.-J. Peng, J.-Q. Huang and Q. Zhang, "Sulfur redox reactions at working interfaces in lithium-sulfur batteries: A perspective," Advanced Materials Interfaces, vol. 6, no. 4, 1802046, 2019. DOI: https://doi.org/10.1002/admi.201802046.

[9] H. Yuan, H.-J. Peng, J.-Q. Huang and Q. Zhang, "Sulfur redox reactions at working interfaces in lithium-sulfur batteries: A perspective," Advanced Materials Interfaces, vol. 6, no. 4, 1802046, 2019. DOI: https://doi.org/10.1002/admi.201802046.

[10] X.-B. Cheng, C. Yan, X.-Q. Zhang, H. Liu and Q. Zhang, "Electronic and ionic channels in working interfaces of lithium metal anodes," ACS Energy Letters, vol. 3, no. 7, pp. 1564-1570, 2018. DOI: https://doi.org/10.1021/acsenergylett.8b00526.

[11] M.-T. F. Rodrigues, G. Babu, H. Gullapalli, K. Kalaga, F. N. Sayed, K. Kato, J. Joyner and P. M. Ajayan, "A materials perspective on Li-ion batteries at extreme temperatures," Nature Energy, vol. 2, no. 8, pp. 1-14, 2017. DOI: https://doi.org/10.1038/nenergy.2017.108.

[12] K. Zhang, G.-H. Lee, M. Park, W. Li and Y.-M. Kang, "Recent developments of the lithium metal anode for rechargeable non-aqueous batteries," Advanced Energy Materials, vol. 6, no. 20, 1600811, 2016. DOI: https://doi.org/10.1002/aenm.201600811.

[13] X.-B. Cheng, R. Zhang, C. Z. Zhao, F. Wei, J. G. Zhang and Q. Zhang, "A review of solid electrolyte interphases on lithium metal anode," Advanced Science, vol. 3, no. 3, 1500213, 2016 . DOI: https://doi.org/10.1002/advs.201500213.

[14] F. Ding, W. Xu, G. L. Graff, J. Zhang, M. L. Sushko, X. Chen, Y. Shao, M. H. Engelhard, Z. Nie, J. Xiao, X. Liu, P. V. Sushko, J. Liu and J. G. Zhang, "Dendrite-free lithium deposition via self-healing electrostatic shield mechanism," Journal of the American Chemical Society, vol. 135, no. 11, pp. 4450-4456, 2013. DOI: https://doi.org/10.1021/ja312241y. 
[15] X. Gu and C. Lai, "One dimensional nanostructures contribute better Li-S and Li-Se batteries: Progress, challenges and perspectives," Energy Storage Materials, vol. 23, pp. 190-224, 2019. DOI: https://doi.org/10.1016/j.ensm.2019.05.013.

[16] K. Pu, X. Zhang, Xi. Qu, J. Hu, H. Li, M. Gao, H. Pan, Y. Liu, "Recently developed strategies to restrain dendrite growth of Li metal anodes for rechargeable batteries," Rare Metal s, vol. 39, no. 6, pp. 616-635, 2020. DOI: https://doi.org/10.1007/s12598-020-01432-2

[17] B. Li, Y. Wang and S. Yang, "A material perspective of rechargeable metallic lithium anodes," Advanced Energy Materials, vol. 8, no. 13, 1702296, 2018. DOI: https://doi.org/10.1002/aenm.201702296.

[18] X. Gu, Z. Yang, S. Qiao, C. Shao X. Ren and J. Y, "Exploiting methylated amino resin as a multifunctional binder for high-performance lithium-sulfur batteries", Rare Metals , 2020. DOI: http://doi.org/10.1007/s12598-020-01409-1

[19] X.-Q. Zhang, X.-B. Cheng, X. Chen, C. Yan and Q. Zhang, "Fluoroethylene carbonate additives to render uniform Li deposits in lithium metal batteries," Advanced Functional Materials, vol. 27, no. 10, 1605989, 2017. DOI: https://doi.org/10.1002/adfm.201605989.

[20] H. Yu, J. Zhao, L. Ben, Y. Zhan, Y. Wu and X. Huang, "Dendrite-free lithium deposition with selfaligned columnar structure in a carbonate-ether mixed electrolyte," ACS Energy Letters,vol. 2, no. 6, pp. 1296-1302, 2017. DOI: https://doi.org/10.1021/acsenergylett.7b00273.

[21] H. Wang, M. Matsui, H. Kuwata, H. Sonoki, Y. Matsuda, X. Shang, Y. Takeda, O. Yamamoto and N. Imanishi, "A reversible dendrite-free high-areal-capacity lithium metal electrode," Nature Communications, vol. 8, no. 1, pp. 1-9, 2017. DOI: https://doi.org/10.1038/ncomms15106.

[22] E. Markevich, G. Salitra, F. Chesneau, M. Schmidt and D. Aurbach, "Very stable lithium metal stripping-plating at a high rate and high areal capacity in fluoroethylene carbonate-based organic electrolyte solution," ACS Energy Letters, vol. 2, no. 6, pp. 1321-1326, $2017 . \quad$ DOI: https://doi.org/10.1021/acsenergylett.7b00300.

[23] H. Dai, X. Gu, J. Dong, C. Wang, C. Lai and S. Sun, "Stabilizing lithium metal anode by octaphenyl polyoxyethylene-lithium complexation," Nature Communications, vol. 11, no. 1, pp. 1-11, 2020. DOI: https://doi.org/10.1038/s41467-020-14505-8.

[24] J. J. Xu, Q. C. Liu, Y. Yu, J. Wang, J. M. Yan and X. B. Zhang, "In situ construction of stable tissuedirected/reinforced bifunctional separator/protection film on lithium anode for lithium-oxygen batteries," Advanced Materials, vol. 29, no. 24, 1606552, 2017. DOI: https://doi.org/10.1002/adma.201606552.

[25] M. Ye, X. Jin, X. Nan, J. Gao and L. Qu, "Paraffin wax protecting 3D non-dendritic lithium for backside-plated lithium metal anode," Energy Storage Materials, vol. 24, pp. 153-159, 2020. DOI: https://doi.org/10.1016/j.ensm.2019.08.024.

[26] K. R. Adair, M. Iqbal, C. Wang, Y. Zhao, M. N. Banis, R. Li, L. Zhang, R. Yang, S. Lu and X. Sun, "Towards high performance Li metal batteries: Nanoscale surface modification of 3D metal hosts for pre-stored Li metal anodes," Nano Energy, vol. 54, pp. 375-382, $2018 . \quad$ DOI: https://doi.org/10.1016/j.nanoen.2018.10.002.

[27] R. Mukherjee, A. V. Thomas, D. Datta, E. Singh, J. Li, O. Eksik, V. B. Shenoy and N. Koratkar, "Defect-induced plating of lithium metal within porous graphene networks," Nature Communications, vol. 5, no. 1, pp. 1-10, 2014. DOI: https://doi.org/10.1038/ncomms4710.

[28] R. Zhang, N. W. Li, X. B. Cheng, Y. X. Yin, Q. Zhang and Y. G. Guo, "Advanced micro/nanostructures for lithium metal anodes," Advanced Science, vol. 4, no. 3, 1600445, 2017. DOI: https://doi.org/10.1002/advs.201600445. 
[29] B. Liu, J.-G. Zhang and W. Xu, "Advancing lithium metal batteries," Joule, vol. 2, no. 5, pp. 833-845, 2018. DOI: https://doi.org/10.1016/j.joule.2018.03.008.

[30] H. Yang, C. Guo, A. Naveed, J. Lei, J. Yang, Y. Nuli and J. Wang, "Recent progress and perspective on lithium metal anode protection," Energy Storage Materials, vol. 14, pp. 199-221, 2018. DOI: https://doi.org/10.1016/j.ensm.2018.03.001.

[31] F. Wu, Y.-X. Yuan, X.-B. Cheng, Y. Bai, Y. Li, C. Wu and Q. Zhang, "Perspectives for restraining harsh lithium dendrite growth: Towards robust lithium metal anodes," Energy Storage Materials,vol. 15, pp. 148-170, 2018. DOI: https://doi.org/10.1016/j.ensm.2018.03.024.

[32] C. Yang, K. Fu, Y. Zhang, E. Hitz and L. Hu, "Protected lithium-metal anodes in batteries: From liquid to solid," Advanced Materials, vol. 29, no. 36, 1701169, 2017. DOI: https://doi.org/10.1002/adma.201701169.

[33] L. Wang, Z. Zhou, X. Yan, F. Hou, L. Wen, W. Luo, J. Liang and S. X. Dou, "Engineering of lithiummetal anodes towards a safe and stable battery," Energy Storage Materials, vol. 14, pp. 22-48, 2018. DOI: https://doi.org/10.1016/j.ensm.2018.02.014.

[34] C. M. Park, J. H. Kim, H. Kim and H. J. Sohn, "Li-alloy based anode materials for Li secondary batteries," Chemical Society Reviews, vol. 39, no. 8, pp. 3115-3141, $2010 . \quad$ DOI: https://doi.org/10.1039/B919877F.

[35] R. A. Huggins, "Alloy negative electrodes for lithium batteries formed in-situ from oxides," Ionics, vol. 3, no. 3-4, pp. 245-255, 1997. DOI: https://doi.org/10.1007/BF02375624.

[36] S. Matsuno, M. Noji, T. Kashiwagi, M. Nakayama and M. Wakihara, "Construction of the ternary phase diagram for the Li-Cu-Sb system as the anode material for a lithium ion battery," Journal of Physical Chemistry C, vol. 111, no. 20, pp. 7548-7553, 2007. DOI: https://doi.org/10.1021/jp070397u.

[37] L. M. L. Fransson, J. T. Vaughey, R. Benedek, K. Edström, J. O. Thomas and M. M. Thackeray, "Phase transitions in lithiated $\mathrm{Cu}_{2} \mathrm{Sb}$ anodes for lithium batteries: an in situ X-ray diffraction study," Electrochemistry Communications, vol. 3, no. 7, pp. 317-323, 2001. DOI: https://doi.org/10.1016/S13882481(01)00140-0.

[38] X.-B. Cheng, H.-J. Peng, J.-Q. Huang, F. Wei and Q. Zhang, "Dendrite-free nanostructured anode: Entrapment of lithium in a 3d fibrous matrix for ultra-stable lithium-sulfur batteries," Small, vol. 10, no. 21, pp. 4257-4263, 2014. DOI: https://doi.org/10.1002/smll.201401837.

[39] H. Liu, X.-B. Cheng, J.-Q. Huang, S. Kaskel, S. Chou, H. S. Park and Q. Zhang, "Alloy anodes for rechargeable alkali-metal batteries: Progress and challenge," ACS Materials Letters, vol. 1, no. 22, pp. 217229, 2019. DOI: https://doi.org/10.1021/acsmaterialslett.9b00118.

[40] J. Zhao, G. Zhou, K. Yan, J. Xie, Y. Li, L. Liao, Y. Jin, K. Liu, P. C. Hsu, J. Wang, H. M. Cheng and Y. Cui, "Air-stable and freestanding lithium alloy/graphene foil as an alternative to lithium metal anodes," Nature Nanotechnology, vol. 12, no. 10, pp. 993-999, 2017. DOI: https://doi.org/10.1038/nnano.2017.129.

[41] A. N. Dey, "Electrochemical alloying of lithium in organic electrolytes," Journal of the Electrochemical Society, vol. 118, no. 10, pp. 1547-1549, 1971. DOI: https://doi.org/10.1149/1.2407783.

[42] J. Yang, M. Winter and J. O. Besenhard, "Small particle size multiphase Li-alloy anodes for lithiumion batteries," Solid State Ionics, vol. 90, no. 1-4, pp. 281-287, 1996. DOI: https://doi.org/10.1016/S01672738(96)00389-X.

[43] H. J. Bang, S. Kim and J. Prakash, "Electrochemical investigations of lithium-aluminum alloy anode in Li/polymer cells," Journal of Power Sources, vol. 92, no. 1-2, pp. 45-49, 2001. DOI: https://doi.org/10.1016/S0378-7753(00)00522-X. 
[44] T. Chen, W. Kong, P. Zhao, H. Lin, Y. Hu, R. Chen, W. Yan and Z. Jin, "Dendrite-free and stable lithium metal anodes enabled by an antimony-based lithiophilic interphase," Chemistry of Materials,2019, vol. 31, no. 18, pp. 7565-7573. DOI: https://doi.org/10.1021/acs.chemmater.9b02356.

[45] D. Wang, W. Zhang, W. Zheng, X. Cui, T. Rojo and Q. Zhang, "Towards high-safe lithium metal anodes: suppressing lithium dendrites via tuning surface energy," Advanced Science, vol. 4, no. 1, 1600168, 2017. DOI: https://doi.org/10.1002/advs.201600168.

[46] J. Zhao, Z. Lu, N. Liu, H. W. Lee, M. T. McDowell and Y. Cui, "Dry-air-stable lithium silicide-lithium oxide core-shell nanoparticles as high-capacity prelithiation reagents," Nature Communications,vol. 5, 5088, 2014. DOI: https://doi.org/10.1038/ncomms6088.

[47] W.-J. Kwak, H.-J. Shin, J. Reiter, N. Tsiouvaras, J. Hassoun, S. Passerini, B. Scrosati and Y.-K. Sun, "Understanding problems of lithiated anodes in lithium oxygen full-cells," Journal of Materials Chemistry A, vol. 4, no. 27, pp. 10467-10471, 2016. DOI: https://doi.org/10.1039/C6TA03013K.

[48] T. Zhang, M. Hong, J. Yang, Z. Xu, J. Wang, Y. Guo and C. Liang, "A high performance lithium-ionsulfur battery with a free-standing carbon matrix supported Li-rich alloy anode," Chemical Science, vol. 9, no. 47, pp. 8829-8835, 2018. DOI: https://doi.org/ 10.1039/C8SC02897D.

[49] Y. Gao, R. Yi, Y. C. Li, J. Song, S. Chen, Q. Huang, T. E. Mallouk and D. Wang, "General method of manipulating formation, composition, and morphology of solid-electrolyte interphases for stable Li-alloy anodes," Journal of the American Chemical Society, vol. 139, no. 48, pp. 17359-17367, 2017. DOI: https://doi.org/10.1021/jacs.7b07584.

[50] J. E. Cloud, Y. Wang, X. Li, T. S. Yoder, Y. Yang and Y. Yang, "Lithium silicide nanocrystals: Synthesis, chemical stability, thermal stability, and carbon encapsulation," Inorganic Chemistry, vol. 53, no. 20, pp. 11289-11297, 2014. DOI: https://doi.org/10.1021/ic501923s.

[51] H. Deng, F. Qiu, X. Li, H. Qin, S. Zhao, P. He and H. Zhou, "A Li-ion oxygen battery with Li-Si alloy anode prepared by a mechanical method," Electrochemistry Communications, vol. 78, pp. 11-15, 2017. DOI: https://doi.org/10.1016/j.elecom.2017.03.010.

[52] S. Iwamura, H. Nishihara, Y. Ono, H. Morito, H. Yamane, H. Nara, T. Osaka and T. Kyotani, "Li-rich Li-Si alloy as a lithium-containing negative electrode material towards high energy lithium-ion batteries," Scientific Reports, vol. 5, 8085, 2015. DOI: https://doi.org/10.1038/srep08085.

[53] M. Wu, J. Jin and Z. Wen, "Influence of a surface modified Li anode on the electrochemical performance of Li-S batteries," RSC Advances, vol. 6, no. 46, pp. 40270-40276, 2016. DOI: https://doi.org/10.1039/C6RA05316E.

[54] M. Wan, S. Kang, L. Wang, H. W. Lee, G. W. Zheng, Y. Cui and Y. Sun, "Mechanical rolling formation of interpenetrated lithium metal/lithium tin alloy foil for ultrahigh-rate battery anode," Nature Communications, vol. 11, no. 1, pp. 829, 2020. DOI: https://doi.org/10.1038/s41467-020-14550-3.

[55] Q. Xu, Y. Yang and H. Shao, "Enhanced cycleability and dendrite-free lithium deposition by addition of sodium ion in electrolyte for lithium metal batteries," Electrochimica Acta,vol. 271, pp. 617-623, 2018. DOI: https://doi.org/10.1016/j.electacta.2018.03.182.

[56] Z. Tu, S. Choudhury, M. J. Zachman, S. Wei, K. Zhang, L. F. Kourkoutis and L. A. Archer, "Fast ion transport at solid-solid interfaces in hybrid battery anodes," Nature Energy, vol. 3, no. 4, pp. 310-316, 2018. DOI: https://doi.org/10.1038/s41560-018-0096-1.

[57] Q. Xu, Y. Yang and H. Shao, "Enhanced cycleability and dendrite-free lithium deposition by adding potassium ion to the electrolyte for lithium metal batteries," Electrochimica Acta,vol. 212, pp. 758-766, 2016. DOI: https://doi.org/10.1016/j.electacta.2016.07.080. 
[58] X. Fan, J. Shao, X. Xiao, X. Wang, S. Li, H. Ge and L. Chen, "SnLi4.4 nanoparticles encapsulated in carbon matrix as high performance anode material for lithium-ion batteries," Nano Energy, vol. 9, pp. 196-203, 2014. DOI: https://doi.org/10.1016/j.nanoen.2014.07.020.

[59] A. H. Whitehead, J. M. Elliott and J. R. Owen, "Nanostructured tin for use as a negative electrode material in Li-ion batteries," Journal of Power Sources, vol. 81-82, pp. 33-38, 1999. DOI: https://doi.org/10.1016/S0378-7753(99)00126-3.

[60] H. Qiu, T. Tang, M. Asif, W. Li, T. Zhang and Y. Hou, "Stable lithium metal anode enabled by lithium metal partial alloying," Nano Energy, vol. 65, 103989, 2019. DOI: https://doi.org/10.1016/j.nanoen.2019.103989.

[61] S. Qu, W. Jia, Y. Wang, C. Li, Z. Yao, K. Li, Y. Liu, W. Zou, F. Zhou, Z. Wang and J. Li, "Air-stable lithium metal anode with sputtered aluminum coating layer for improved performance," Electrochimica Acta, vol. 317, pp. 120-127, 2019. DOI: https://doi.org/10.1016/j.electacta.2019.05.138.

[62] H. Kim, J. T. Lee, D.-C. Lee, M. Oschatz, W. I. Cho, S. Kaskel and G. Yushin, "Enhancing performance of Li-S cells using a Li-Al alloy anode coating," Electrochemistry Communications, vol. 36, pp. 38-41, 2013. DOI: https://doi.org/10.1016/j.elecom.2013.09.002.

[63] J. Sun, Q. Zeng, R. Lv, W. Lv, Q.-H. Yang, R. Amal and D.-W. Wang, "A Li-ion sulfur full cell with ambient resistant Al-Li alloy anode," Energy Storage Materials, vol. 15, pp. 209-217, 2018. DOI: https://doi.org/10.1016/j.ensm.2018.04.003.

[64] N. Kumagai, Y. Kikuchi and K. Tanno, "Electrochemical investigation of the diffusion of lithium in $\beta$ -LiAl alloy at room temperature," Journal of Applied Electrochemistry, vol. 22, no. 8, pp. 728-732, 1992. DOI: https://doi.org/10.1007/BF01027501.

[65] B. Duan, W. Wang, H. Zhao, A. Wang, M. Wang, K. Yuan, Z. Yu and Y. Yang, "Li-B Alloy as Anode Material for Lithium/Sulfur Battery," ECS Electrochemistry Letters, vol. 2, no. 6, pp. A47-A51, 2013. DOI: https://doi.org/10.1149/2.005306eel.

[66] X. Zhang, W. Wang, A. Wang, Y. Huang, K. Yuan, Z. Yu, J. Qiu and Y. Yang, "Improved cycle stability and high security of Li-B alloy anode for lithium-sulfur battery," Journal of Materials Chemistry A, vol. 2, no. 30, pp. 11660-11665, 2014. DOI: https://doi.org/10.1039/C4TA01709A.

[67] S. Choudhury, Z. Tu, S. Stalin, D. Vu, K. Fawole, D. Gunceler, R. Sundararaman and L. A. Archer, "Electroless formation of hybrid lithium anodes for fast interfacial ion transport," Angewandte Chemie International Edition, vol. 56, no. 42, pp. 13070-13077, 2017. DOI: https://doi.org/10.1002/anie.201707754.

[68] A. L. Santhosha, L. Medenbach, J. R. Buchheim and P. Adelhelm, "The indium-lithium electrode in solid-state lithium-ion batteries: Phase formation, redox potentials, and interface stability," Batteries 83 Supercaps, vol. 2, no. 6, pp. 524-529, 2019. DOI: https://doi.org/10.1002/batt.201800149.

[69] W. Weppner and R. A. Huggin, "Thermodynamic properties of the intermetallic systems lithiumantimony and lithium-bismuth," Journal of the Electrochemical Society, vol. 125, no. 1, pp. 7-14, 1978. DOI: https://doi.org/10.1149/1.2131401.

[70] J. O. Besenhard and H. P. Fritz, "Reversibles elektrochemisches legieren von metallen der V. hauptgruppe in organischen Li+-Lösungen," Electrochimica Acta, vol. 20, no. 6-7, pp. 513-517, 1975. DOI: https://doi.org/10.1016/0013-4686(75)90042-0.

[71] W. Xianming, T. Nishina and I. Uchida, "Lithium alloy formation at bismuth thin layer electrode and its kinetics in propylene carbonate electrolyte," Journal of Power Sources, vol. 104, no. 1, pp. 90-96, 2002. DOI: https://doi.org/10.1016/S0378-7753(01)00876-X.

[72] A. G. Morachevskii, "Lithium-antimony alloys: Phase diagram, thermodynamic properties, electrochemical behavior in molten and nonaqueous electrolytes, and use in lithium-ion batteries," Russian Journal of 
Applied Chemistry, vol. 88, no. 11, pp. 1737-1749, 2016. DOI: https://doi.org/10.1134/S10704272150110014.

[73] R. A. Huggins, "Lithium alloy negative electrodes," Journal of Power Sources, vol. 81-82, pp. 13-19, 1999. DOI: https://doi.org/10.1016/S0378-7753(99)00124-X.

[74] J. K. Stark, Y. Ding and P. A. Kohl, "Dendrite-free electrodeposition and reoxidation of lithium-sodium alloy for metal-anode battery," Journal of the Electrochemical Society,vol. 158, no. 10, pp. A1100-A1105, 2011. DOI: https://doi.org/10.1149/1.3622348.

[75] K. P. Doyle, C. M. Lang, K. Kim and P. A. Kohl, "Dentrite-free electrochemical deposition of Li-Na alloys from an ionic liquid electrolyte," Journal of the Electrochemical Society, vol. 153, no. 7, pp. A1353-A1357, 2006. DOI: https://doi.org/10.1149/1.2199444.

[76] T. Krauskopf, B. Mogwitz, C. Rosenbach, W. G. Zeier and J. Janek, "Diffusion limitation of lithium metal and Li-Mg alloy anodes on LLZO type solid electrolytes as a function of temperature and pressure," Advances Energy Materials, vol. 9, no. 44, 1902568, 2019. DOI: https://doi.org/10.1002/aenm.201902568.

[77] L. L. Kong, L. Wang, Z. C. Ni, S. Liu, G. R. Li and X. P. Gao, "Lithium-magnesium alloy as a stable anode for lithium-sulfur battery," Advances Functional Materials, vol. 29, no. 13, 1808756, 2019. DOI: https://doi.org/10.1002/adfm.201808756.

[78] Y. Zhang, K. S. R. Chandran, M. Jagannathan, H. Z. Bilheux and J. C. Bilheux, "The nature of electrochemical delithiation of $\mathrm{Li}-\mathrm{Mg}$ alloy electrodes: neutron computed tomography and analytical modelling of Li diffusion and delithiation phenomenon," Journal of The Electrochemical Society, vol. 164, no. 2, pp. A28-A38, 2017. DOI: https://doi.org/10.1149/2.0051702jes.

[79] T. J. Richardson and G. Chen, "Solid solution lithium alloy cermet anodes," Journal of Power Sources, vol. 174, no. 2, pp. 810-812, 2007. DOI: https://doi.org/10.1016/j.jpowsour.2007.06.106.

[80] Z. Shi, M. Liu, D. Naik and J. L. Gole, "Electrochemical properties of Li-Mg alloy electrodes for lithium batteries," Journal Power Sources, vol. 92, no. 1-2, pp. 70-80, 2001. DOI: https://doi.org/10.1016/S03787753(00)00521-8.

[81] M. Jagannathan and K. S. R. Chandran, "Electrochemical charge/discharge behavior and phase transitions during cell cycling of $\mathrm{Li}(\mathrm{Mg})$ alloy anodes for high capacity Li ion batteries," Journal of The Electrochemical Society, vol. 160, no. 10, pp. A1922-A1926, 2013. DOI: https://doi.org/10.1149/2.006311jes.

[82] J. Wang, P. King and R. A. Huggins, "Investigations of binary lithium-zinc, lithium-cadmium and lithium-lead alloys as negative electrodes in organic solvent-based electrolyte," Solid State Ionics, vol. 20, no. 3, pp. 185-189, 1986. DOI: https://doi.org/10.1016/0167-2738(86)90212-2.

[83] C. Chen, Y. Yang and H. Shao, "Enhancement of the lithium cycling capability using Li-Zn alloy substrate for lithium metal batteries," Electrochimica Acta, vol. 137, pp. 476-483, 2014. DOI: https://doi.org/10.1016/j.electacta.2014.06.006.

[84] "Inward-growth plating of lithium driven by solid-solution based alloy phase for highly reversible lithium metal anode," ArXiv Preprint ArXiv, October 2019. [Online]. Available: https://arxiv.org/abs/1910.13159.

[85] K. Yan, Z. Lu, H.-W. Lee, F. Xiong, P.-C. Hsu, Y. Li, J. Zhao, S. Chu and Y. Cui, "Selective deposition and stable encapsulation of lithium through heterogeneous seeded growth," Nature Energy,vol. 1, no. 3, pp. 1-8, 2016. DOI: https://doi.org/10.1038/nenergy.2016.10.

[86] J. L. Ma, F. L. Meng, Y. Yu, D. P. Liu, J. M. Yan, Y. Zhang, X. B. Zhang and Q. Jiang, "Prevention of dendrite growth and volume expansion to give high-performance aprotic bimetallic Li-Na alloy- $\mathrm{O}_{2}$ batteries," Nature chemistry, vol. 11, no. 1, pp. 64-70, 2019. DOI: https://doi.org/10.1038/s41557-018-0166-9.

[87] Y. Xu, S. Zhao, G. Zhou, W. Chen, F. Zhou, Z. Rong, Y. Wu, J. Li, J. Guo and Y. Zhang, "Solubilitydependent protective effects of binary alloys for lithium anode," ACS Applied Energy Materials,vol. 3, no. 3, pp. 2278-2284, 2020. DOI: https://doi.org/10.1021/acsaem.9b02125. 
[88] Y. Hashimoto, "Preparation of $\mathrm{Li}_{4.4} \mathrm{Ge}_{x} \mathrm{Si}_{1-x}$ alloys by mechanical milling process and their properties as anode materials in all-solid-state lithium batteries," Solid State Ionics, vol. 175, no. 1-4, pp. 177-180, 2004. DOI: https://doi.org/10.1016/j.ssi.2004.08.022.

[89] S. Liu, J. Yang, L. Yin, Z. Li, J. Wang and Y. Nuli, "Lithium-rich $\mathrm{Li}_{2.6} \mathrm{BMg}_{0.05}$ alloy as an alternative anode to metallic lithium for rechargeable lithium batteries," Electrochimica Acta, vol. 56, no. 24, pp. 89008905, 2011. DOI: https://doi.org/10.1016/j.electacta.2011.07.109.

[90] Y. Liu, R. Ma, Y. He, M. Gao and H. Pan, "Synthesis, structure transformation, and electrochemical properties of $\mathrm{Li}_{2} \mathrm{MgSi}$ as a novel anode for Li-ion batteries," Advanced Functional Materials, vol. 24, no. 25, pp. 3944-3952, 2014. DOI: https://doi.org/10.1002/adfm.201304287.

[91] K. D. Kepler, J. T. Vaughey and M. M. Thackeray, " $\mathrm{Li}_{x} \mathrm{Cu}_{6} \mathrm{Sn}_{5}(0<x<13)$ : An intermetallic insertion electrode for rechargeable lithium batteries," Electrochemical and Solid-State Letters, vol. 2, no. 7, pp. 307309, 1999. DOI: https://doi.org/10.1149/1.1390819.

[92] H. Li, L. Shi, Q. Wang, L. Chen and X. Huang, "Nano-alloy anode for lithium ion batteries," Solid State Ionics, vol. 148, no. 3-4, pp. 247-258, 2002. DOI: https://doi.org/10.1016/S0167-2738(02)00061-9.

[93] Y. Gui, Z. Liu, L. Chen, H. Huang and H. Ning, "Effect of Mg on the skeleton structure and properties of Li-B alloy for lithium secondary battery," Journal of Functional Materials, vol. 50, no. 9, pp. 09027-09032, 2019. DOI: https://doi.org/10.3969/j.issn.1001-9731.2019.09.005.

[94] S. Liu, X. Zhang, R. Li, L. Gao and J. Luo, "Dendrite-free Li metal anode by lowering deposition interface energy with $\mathrm{Cu}_{99} \mathrm{Zn}$ alloy coating," Energy Storage Materials,vol. 14, pp. 143-148, 2018. DOI: https://doi.org/10.1016/j.ensm.2018.03.004.

[95] I. Chumak, G. Dmytriv, V. Pavlyuk, S. Oswald, J. Eckert, H. Trill, H. Eckert, H. Pauly and H. Ehrenberg, " $\beta-\mathrm{Li}_{2} \mathrm{Zn} 5$ : a low symmetric polar intermetallic compound," Journal of Materials Research, vol. 25, no. 19, pp. 1492-1499, 2011. DOI: https://doi.org/10.1021/acs.inorgchem.9b01266.

[96] O. Crosnier, C. Mounsey, P. S. Herle, N. Taylor and L. F. Nazar, "Crystal structure and electrochemical behavior of $\mathrm{Li}_{2} \mathrm{CuP}$ : A surprising reversible crystalline-amorphous transformation," Chemistry of Materials, vol. 15, no. 26, pp. 4890-4892, 2003. DOI: https://doi.org/10.1021/cm034619m.

[97] J. T. Vaughey, J. O. Hara and M. M. Thackeray, "Intermetallic insertion electrodes with a zinc blendetype structure for Li batteries: A study of $\mathrm{Li}_{x} \mathrm{InSb}$ (0[?]x [?]3)," Electrochemical and Solid-State Letters, vol. 3, no. 1, pp. 13-16, 2000. DOI: https://doi.org/10.1149/1.1390944.

[98] M. Zhu, B. Li, S. Li, Z. Du, Y. Gong and S. Yang, "Dendrite-free metallic lithium in lithiophilic carbonized metal-organic frameworks," Advanced Energy Materials, vol. 8, no. 18, 1703505, 2018. DOI: https://doi.org/10.1002/aenm.201703505.

[99] P. Xue, S. Liu, X. Shi, C. Sun, C. Lai, Y. Zhou, D. Sui, Y. Chen and J. Liang, "A hierarchical silver-nanowire-graphene host enabling ultrahigh rates and superior long-term cycling of lithium-metal composite anodes," Advanced Materials, vol. 30, no. 44, 1804165, 2018. DOI: https://doi.org/10.1002/adma.201804165.

[100] Y. Liu, D. Lin, Z. Liang, J. Zhao, K. Yan and Y. Cui, "Lithium-coated polymeric matrix as a minimum volume-change and dendrite-free lithium metal anode," Nature Communications, vol. 7, 10992, 2016. DOI: https://doi.org/10.1038/ncomms10992.

[101] Z. Luo, C. Liu, Y. Tian, Y. Zhang, Y. Jiang, J. Hu, H. Hou, G. Zou and X. Ji, "Dendrite-free lithium metal anode with lithiophilic interphase from hierarchical frameworks by tuned nucleation," Energy Storage Materials, vol. 27, pp. 124-132, 2020. DOI: https://doi.org/10.1016/j.ensm.2020.01.025.

[102] C. Wu, H. Huang, W. Lu, Z. Wei, X. Ni, F. Sun, P. Qing, Z. Liu, J. Ma, W. Wei, L. Chen, C. Yan and L. Mai, "Mg doped Li-LiB alloy with in situ formed lithiophilic LiB skeleton for lithium metal batteries," 
Advanced Science, vol. 7, 1902643, 2020. DOI: https://doi.org/10.1002/advs.201902643.

[103] X. Wang, Z. Pan, Y. Wu, X. Ding, X. Hong, G. Xu, M. Liu, Y. Zhang and W. Li, "Infiltrating lithium into carbon cloth decorated with zinc oxide arrays for dendrite-free lithium metal anode," Nano Research, vol. 12, no. 3, pp. 525-529, 2018. DOI: https://doi.org/10.1007/s12274-018-2245-z.

[104] H. Ye, Z. J. Zheng, H. R. Yao, S. C. Liu, T. T. Zuo, X. W. Wu, Y. X. Yin, N. W. Li, J. J. Gu, F. F. Cao and Y. G. Guo, "Guiding uniform Li plating/stripping through lithium-aluminum alloying medium for long-life Li metal batteries," Angewandte Chemie International Edition, vol. 58, no. 4, pp. 1094-1099, 2019. DOI: https://doi.org/10.1002/ange.201811955.

[105] N. Zhang, S.-H. Yu and H. D. Abruña, "Regulating lithium nucleation and growth by zinc modified current collectors," Nano Research, vol. 13, no. 1, pp. 45-51, 2019. DOI: https://doi.org/10.1007/s12274019-2567-7.

[106] C. Wei, H. Fei, Y. An, Y. Tao, J. Feng and Y. Qian, "Uniform Li deposition by regulating the initial nucleation barrier via a simple liquid-metal coating for a dendrite-free Li-metal anode," Journal of Materials Chemistry A, vol. 7, no. 32, pp. 18861-18870, 2019. DOI: https://doi.org/10.1039/C9TA06663B.

[107] J. Zhao, Z. Lu, H. Wang, W. Liu, H. W. Lee, K. Yan, D. Zhuo, D. Lin, N. Liu and Y. Cui, "Artificial solid electrolyte interphase-protected $\mathrm{Li}_{x} \mathrm{Si}$ nanoparticles: An efficient and stable prelithiation reagent for lithium-ion batteries," Journal of the American Chemical Society, vol. 137, no. 26, pp. 8372-8375, 2015. DOI: https://doi.org/10.1021/jacs.5b04526.

[108] J. Zhao, L. Liao, F. Shi, T. Lei, G. Chen, A. Pei, J. Sun, K. Yan, G. Zhou, J. Xie, C. Liu, Y. Li, Z. Liang, Z. Bao and Y. Cui, "Surface fluorination of reactive battery anode materials for enhanced stability," Journal of the American Chemical Society, vol. 139, no. 33, pp. 11550-11558, 2017. DOI: https://doi.org/10.1021/jacs.7b05251.

[109] H. Guo, G. Hou, D. Li, Q. Sun, Q. Ai, P. Si, G. Min, J. Lou, J. Feng and L. Ci, "High current enabled stable lithium anode for ultralong cycling life of lithium-oxygen batteries," ACS Applied Materials E Interfaces, vol. 11, no. 34, pp. 30793-30800, 2019. DOI: https://doi.org/10.1021/acsami.9b08153.

[110] X. Liang, Q. Pang, I. R. Kochetkov, M. S. Sempere, H. Huang, X. Sun and L. F. Nazar, "A facile surface chemistry route to a stabilized lithium metal anode," Nature Energy , vol. 2, no. 9, 17119, 2017. DOI: https://doi.org/10.1038/nenergy.2017.119.

[111] Y. X. Ren, L. Zeng, H. R. Jiang, W. Q. Ruan, Q. Chen and T. S. Zhao, "Rational design of spontaneous reactions for protecting porous lithium electrodes in lithium-sulfur batteries," Nature Communications, vol. 10, no. 1, pp. 1-10, 2019. DOI: https://doi.org/10.1038/s41467-019-11168-y.

[112] F. Li, Y. H. Tan, Y. C. Yin, T. W. Zhang, L. L. Lu, Y. H. Song, T. Tian, B. Shen, Z. X. Zhu and H. B. Yao, "A fluorinated alloy-type interfacial layer enabled by metal fluoride nanoparticle modification for stabilizing Li metal anodes," Chemical Science,vol. 10, no. 42, pp. 9735-9739, 2019. DOI: https://doi.org/10.1039/C9SC01845J.

[113] Y. Liu, X. Xu, X. Jiao, L. Guo, Z. Song, S. Xiong and J. Song, "LixGe containing ion-conductive hybrid skin for high rate lithium metal anode," Chemical Engineering Journal, vol. 371, pp. 294-300, 2019. DOI: https://doi.org/10.1016/j.cej.2019.04.068.

[114] B. Xu, Z. Liu, J. Li, X. Huang, B. Qie, T. Gong, L. Tan, X. Yang, D. Paley, M. Dontigny, K. Zaghib, X. Liao, Q. Cheng, H. Zhai, X. Chen, L.-Q. Chen, C.-W. Nan, Y.-H. Lin and Y. Yang, "Engineering interfacial adhesion for high-performance lithium metal anode," Nano Energy, vol. 67, 104242, 2020. DOI: https://doi.org/10.1016/j.nanoen.2019.104242.

[115] G. Hou, C. Ci, D. Salpekar, Q. Ai, Q. Chen, H. Guo, L. Chen, X. Zhang, J. Cheng, K. Kato, R. Vajtai, P. Si, G. Babu, L. Ci and P. M. Ajayan, "Stable lithium metal anode enabled by an artifici- 
al multi-phase composite protective film," Journal of Power Sources, vol. 448, 227547, 2020. DOI: https://doi.org/10.1016/j.jpowsour.2019.227547.

[116] K. Liao, S. Wu, X. Mu, Q. Lu, M. Han, P. He, Z. Shao and H. Zhou, "Developing a "wate-defendable" and "dendrite-free" lithium-metal anode using a simple and promising $\mathrm{GeCl}_{4}$ pretreatment method," Advanced Materials, vol. 30, no. 36, 1705711, 2018. DOI: https://doi.org/10.1002/adma.201705711.

[117] F. Guo, C. Wu, H. Chen, F. Zhong, X. Ai, H. Yang and J. Qian, "Dendrite-free lithium deposition by coating a lithiophilic heterogeneous metal layer on lithium metal anode," Energy Storage Materials, vol. 24, pp. 635-643, 2020. DOI: https://doi.org/10.1016/j.ensm.2019.06.010.

[118] L. Ma, M. S. Kim and L. A. Archer, "Stable artificial solid electrolyte interphases for lithium batteries," Chemistry of Materials, vol. 29, no. 10, pp. 4181-4189, 2017. DOI: https://doi.org/10.1021/acs.chemmater.6b03687.

[119] Z. Jiang, L. Jin, Z. Han, W. Hu, Z. Zeng, Y. Sun and J. Xie, "Facile generation of polymer-alloy hybrid layers for dendrite-free lithium-metal anodes with improved moisture stability," Angewandte Chemie International Edition, vol. 58, no. 33, pp. 11374-11378, 2019. DOI: https://doi.org/10.1002/anie.201905712.

[120] "Facile construction of a hybrid artificial protective layer for stable lithium metal anode," Chemical Engineering Journal , pp. 123542 2019. DOI: https://doi.org/10.1016/j.cej.2019.123542.

[121] H. Zhong, L. Sang, F. Ding, J. Song and Y. Mai, "Conformation of lithium-aluminium alloy interphaselayer on lithium metal anode used for solid state batteries," Electrochimica Acta, vol. 277, pp. 268-275, 2018. DOI: https://doi.org/10.1016/j.electacta.2018.04.191.

[122] H. Zhong, Y. Wu, F. Ding, L. Sang and Y. Mai, "An artificial Li-Al interphase layer on LiB alloy for stable lithium-metal anode," Electrochimica Acta, vol. 304, pp. 255-262, 2019. DOI: https://doi.org/10.1016/j.electacta.2019.03.009.

[123] C. Wang, Y. Gong, B. Liu, K. Fu, Y. Yao, E. Hitz, Y. Li, J. Dai, S. Xu, W. Luo, E. D. Wachsman and L. $\mathrm{Hu}$, "Conformal, nanoscale $\mathrm{ZnO}$ surface modification of garnet-based solid-state electrolyte for lithium metal anodes," Nano Letters, vol. 17, no. 1, pp. 565-571, 2017. DOI: https://doi.org/10.1021/acs.nanolett.6b04695.

[124] C. Yang, H. Xie, W. Ping, K. Fu, B. Liu, J. Rao, J. Dai, C. Wang, G. Pastel and L. Hu, "An electron/ion dual-conductive alloy framework for high-rate and high-capacity solid-state lithium-metal batteries," Advanced Materials, vol. 31, no. 3, 1804815, 2019. DOI: https://doi.org/10.1002/adma.201804815.

[125] C. Wang, H. Xie, L. Zhang, Y. Gong, G. Pastel, J. Dai, B. Liu, E. D. Wachsman and L. Hu, "Universal soldering of lithium and sodium alloys on various substrates for batteries," Advanced Energy Materials, vol. 8, no. 6, 1701963, 2018. DOI: https://doi.org/10.1002/aenm.201701963.

[126] W. Luo, Y. Gong, Y. Zhu, Y. Li, Y. Yao, Y. Zhang, K. K. Fu, G. Pastel, C. F. Lin, Y. Mo, E. D. Wachsman and $\mathrm{L}$. Hu, "Reducing interfacial resistance between garnet-structured solid-state electrolyte and Li-metal anode by a germanium layer," Advanced Materials,vol. 29, no. 22, 1606042, 2017. DOI: https://doi.org/10.1002/adma.201606042.

[127] H. Lee, X. Ren, C. Niu, L. Yu, M. H. Engelhard, I. Cho, M.-H. Ryou, H. S. Jin, H.-T. Kim, J. Liu, W. $\mathrm{Xu}$ and J.-G. Zhang, "Suppressing lithium dendrite growth by metallic coating on a separator," Advanced Functional Materials, vol. 27, no. 45, 1704391, 2017. DOI: https://doi.org/10.1002/adfm.201704391.

[128] Z. Hu, F. Liu, J. Gao, W. Zhou, H. Huo, J. Zhou and L. Li, "Dendrite-free lithium plating induced by in situ transferring protection layer from separator," Advanced Functional Materials, vol. 30, no. 5, 1907020, 2019. DOI: https://doi.org/10.1002/adfm.201907020.

[129] J. O. Besenhard, P. Komenda, A. Paxinos and E. Wudy, "Binary and ternary Li-alloys as anode materials in rechargeable organic electrolyte Li-batteries," Solid State lonics, vol. 18-19, pp. 823-827, 1986. DOI: https://doi.org/10.1016/0167-2738(86)90270-5. 
[130] F. Sun, D. Zhou, X. He, M. Osenberg, K. Dong, L. Chen, S. Mei, A. Hilger, H. Markötter, Y. Lu, S. Dong, S. Marathe, C. Rau, X. Hou, J. Li, M. C. Stan, M. Winter, R. Dominko and I. Manke, "The morphological reversibility of modified-Li based anode for next generation batteries," ACS Energy Letters, vol. 5, no. 1, pp. 152-161, 2019. DOI: https://doi.org/10.1021/acsenergylett.9b02424.

[131] S. Jiang, Y. Lu, Y. Lu, M. Han, H. Li, Z. Tao, Z. Niu and J. Chen, "Nafion/titanium dioxide-coated lithium anode for stable lithium-sulfur batteries," Chemistry-An Asian Journal, vol. 13, no. 10, pp. 13791385, 2018. DOI: https://doi.org/10.1002/asia.201800326.

[132] S. Matsuda, Y. Kubo, K. Uosaki and S. Nakanishi, "Lithium-metal deposition/dissolution within internal space of CNT 3D matrix results in prolonged cycle of lithium-metal negative electrode," Carbon, vol. 119, pp. 119-123, 2017. DOI: https://doi.org/10.1016/j.carbon.2017.04.032.

[133] M. S. Kim, Deepika, S. H. Lee, M.-S. Kim, J.-H. Ryu, K.-R. Lee, L. A. Archer and W. I. Cho, "Enabling reversible redox reactions in electrochemical cells using protected LiAl intermetallics as lithium metal anodes," Science Advances, vol. 5, no. 10, eaax5587, 2019. DOI: https://doi.org/10.1126/sciadv.aax5587.

[134] D. Lin, Y. Liu, A. Pei and Y. Cui, "Nanoscale perspective: Materials designs and understandings in lithium metal anodes," Nano Research, vol. 10, no. 12, pp. 4003-4026, 2017. DOI: https://doi.org/10.1007/s12274017-1596-1.

[135] W.-Y. Tsai, R. Lin, S. Murali, L. Li Zhang, J. K. McDonough, R. S. Ruoff, P.-L. Taberna, Y. Gogotsi and P. Simon, "Outstanding performance of activated graphene based supercapacitors in ionic liquid electrolyte from -50 to $80{ }^{\circ} \mathrm{C}, "$ Nano Energy, vol. 2, no. 3, pp. 403-411, 2013. DOI: https://doi.org/10.1016/j.nanoen.2012.11.006.

[136] R. Younesi, G. M. Veith, P. Johansson, K. Edström and T. Vegge, "Lithium salts for advanced lithium batteries: Li-metal, Li-O ${ }_{2}$, and Li-S," Energy 83 Environmental Science, vol. 8, no. 7, pp. 1905-1922, 2015. DOI: https://doi.org/10.1039/C5EE01215E. 